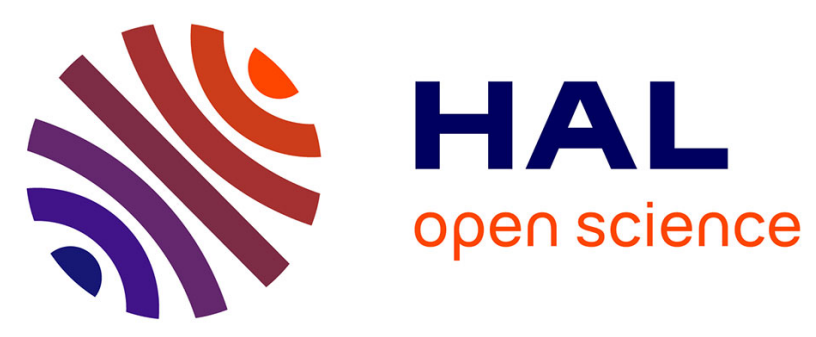

\title{
C F bond breaking by bare actinide monocations in the gas phase: a relativistic DFT study
}

Farida Kias, Fatiha Talbi, Aziz Elkechai, Abdou Boucekkine

\section{To cite this version:}

Farida Kias, Fatiha Talbi, Aziz Elkechai, Abdou Boucekkine. C F bond breaking by bare actinide monocations in the gas phase: a relativistic DFT study. Computational and Theoretical Chemistry, 2017, 1118, pp.133-143. 10.1016/j.comptc.2017.09.002 . hal-01622328

HAL Id: hal-01622328

https://hal-univ-rennes1.archives-ouvertes.fr/hal-01622328

Submitted on 24 Oct 2017

HAL is a multi-disciplinary open access archive for the deposit and dissemination of scientific research documents, whether they are published or not. The documents may come from teaching and research institutions in France or abroad, or from public or private research centers.
L'archive ouverte pluridisciplinaire HAL, est destinée au dépôt et à la diffusion de documents scientifiques de niveau recherche, publiés ou non, émanant des établissements d'enseignement et de recherche français ou étrangers, des laboratoires publics ou privés. 


\section{C-F bond breaking by bare actinide monocations in the gas phase: a relativistic DFT study}

\section{Farida Kias $^{\text {a }}$ FatihaTalbi $^{\text {a }}$, Aziz Elkechai ${ }^{a^{*}}$, Abdou Boucekkine ${ }^{b^{*}}$.}

(a) Laboratoire de physique et chimie quantique, Faculté des sciences, Université Mouloud Mammeri de Tizi-Ouzou, 15000 Tizi-Ouzou, Algeria

(b) Institut des sciences chimiques de Rennes, UMR 6226 CNRS-Université de Rennes 1, Campus de Beaulieu, 35042 Rennes Cedex, France

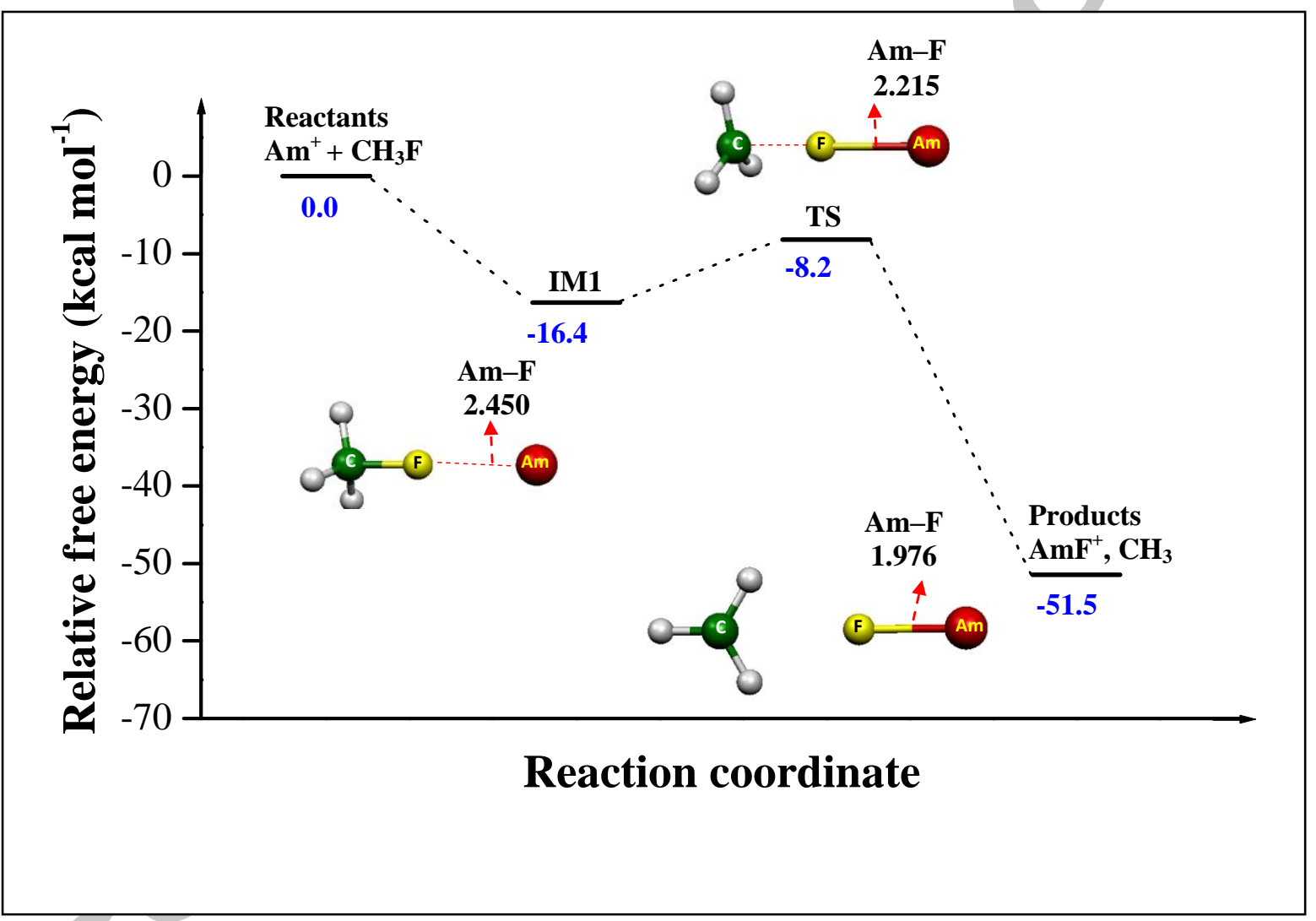

\section{Highlights}

Context of accidental radioactive dissemination

Activation of C-F strong bond by actinide ions investigated using DFT computations

$\mathrm{CH}_{3} \mathrm{~F}+\mathrm{An}^{+}$exergonic reactions with low barriers leading to $\mathrm{An}-\mathrm{F}^{+}$formation

Corresponding authors: A.E. : azizelkechai@yahoo.fr

A.B.: abdou.boucekkine@univ-rennes1.fr 


\section{Abstract}

Investigations of the $\mathrm{C}-\mathrm{F}$ bond activation by actinide monocation $\mathrm{An}^{+}(\mathrm{An}=\mathrm{Ac}, \mathrm{Th}, \mathrm{Pa}, \mathrm{U}$, $\mathrm{Np}, \mathrm{Pu}$ and $\mathrm{Am}$ ) are carried out using relativistic density functional theory (DFT) computations. Originally, the aim of the study is to compare the ability of different actinide ions to break strong bonds particularly in the context of accidental radioactive dissemination. The $\mathrm{An}^{+}$reaction with the fluorinated hydrocarbon $\mathrm{CH}_{3} \mathrm{~F}$ was selected as a representative system in this context. Unexpectedly, the considered $\mathrm{An}^{+}$were found to react differently. Via linear transit (LT) and intrinsic reaction coordinate (IRC) calculations, three reaction mechanisms for the $\mathrm{C}-\mathrm{F}$ bond activation, leading to the $\mathrm{An}-\mathrm{F}^{+}$formation, were revealed; the first one, i.e. 'harpoon' mechanism which was observed in the case of $\mathrm{Ae}^{+}, \mathrm{Pu}^{+}, \mathrm{Am}^{+}$, while the second called 'insertion-elimination' mechanism concerned the case of $\mathrm{Th}^{+}, \mathrm{Pa}^{+}, \mathrm{U}^{+}$and $\mathrm{Np}^{+}$. DFT computations highlight the particular case of the $\mathrm{Ac}^{+}$system which presents two different mechanisms according to its spin state: a mechanism qualified as 'harpoon-like' for the triplet state and an 'insertion-elimination' mechanism for the singlet state. The activation barrier for the fluorine elimination from $\mathrm{CH}_{3} \mathrm{~F}$ is weak for all the studied systems, from 0.9 $\mathrm{kcal} / \mathrm{mol}$ for $\mathrm{Th}^{+}$to $8.2 \mathrm{kcal} / \mathrm{mol}$ for $\mathrm{Am}^{+}$. $\mathrm{Th}^{+}$is found as the most effective ion to activate the $\mathrm{C}-\mathrm{F}$ bond and a considerable exergonic character $(-81.5 \mathrm{kcal} / \mathrm{mol})$ for this reaction is expected. The performed orbital, population and charge analyses permitted to reveal the role of the actinide $7 \mathrm{~s}, 6 \mathrm{~d}$ and $5 \mathrm{f}$ orbitals and of electron transfers during the reaction.

Keywords: actinide cations; DFT calculations; C-F bond activation; reaction mechanisms.

\section{Introduction}

The activation/breaking of strong bonds is a permanent challenge in chemical catalysis. In this context, although transition metal complexes have been widely used and studied for their catalytic ability, very few studies were carried out considering lanthanide and actinide species [1-8]. Experimentally, the study of the reactivity of actinide species towards the activation of strong bonds is difficult to carry out; to our knowledge only some gas phase reactions of lanthanide ions and few actinide ions have been studied by Gibson's group using mass spectrometry techniques [9]. Theoretically also, several factors are at the origin of the relatively small number of computational studies, in particular the issue related to the presence of open shells (4f for lanthanides and $5 \mathrm{f}$ for the actinides) and that associated to relativistic effects [10], even if it is recognized that lanthanide $4 \mathrm{f}$ electrons do not take part in 
the bonding, contrarily to what was shown for $5 f$ actinide electrons [11]. Thus, the understanding of the activation mechanism of hydrocarbons strong bonds, in particular the $\mathrm{C}-\mathrm{F}$ and $\mathrm{C}-\mathrm{H}$ bonds, by lanthanide or actinide monocations, remains a complex task for theoretical chemists and experimentalists [12-14]. Among the rare studies, the reactivity of lanthanide ions for activating $\mathrm{C}-\mathrm{H}$ and $\mathrm{C}-\mathrm{F}$ bonds and actinide ions for activating $\mathrm{C}-\mathrm{H}$ and $\mathrm{C}-\mathrm{C}$ bonding gas phase has received a particular attention since the end of the 90 's. Thus, in 1996, Cornehl and co--workers [15] undertook an experimental investigation on the gas-phase reactivity of lanthanide cations with fluorinated hydrocarbons using Fourier transform ion cyclotron resonance mass spectroscopy. They concluded that the $\mathrm{C}-\mathrm{F}$ bond activation comes mainly from $\mathrm{F}$ atom abstraction via the "harpoon mechanism" as depicted in Scheme 1:

$$
\operatorname{Ln}^{+}+\boldsymbol{R F} \rightarrow[\operatorname{Ln} \ldots F-R \rightarrow \operatorname{Ln}-\boldsymbol{F} \ldots . R]^{+} \rightarrow \operatorname{LnF}^{+}+R
$$

IM1 TS

Scheme 1: Harpoon mechanism

At the beginning of the reaction, the $\mathrm{Ln}^{+}$cation coordinates directly to the fluorine atom of $\mathrm{CH}_{3}-\mathrm{F}$ (with $\mathrm{R}=\mathrm{CH}_{3}$ in Scheme 1) leading to the formation of an intermediate complex then to a transition state to give the final products $\mathrm{LnF}^{+}$and the methyl species.

A decade later, in their experimental study, thanks to inductive-coupled plasma/selected-ion flow tandem mass spectrometry, Koyanagi and co-workers [16] pointed out the insertionelimination mechanism occurring in methyl fluoride $\mathrm{C}-\mathrm{F}$ bond activation by lanthanide cations (excluding $\mathrm{Pm}^{+}$) according to Scheme 2:

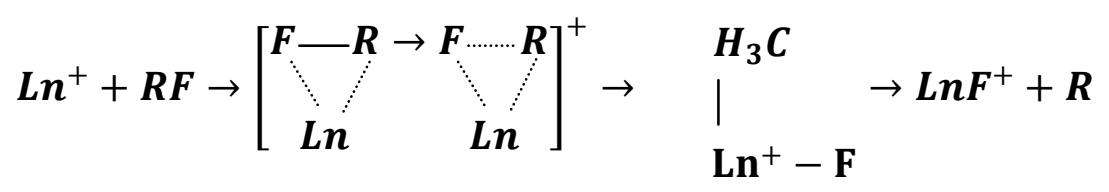

IM1 TS IM2

Scheme 2: Insertion-elimination mechanism 
This mechanism involves the formation of a three-membered cyclic ion and a three-centered transition state leading to the insertion of $\mathrm{Ln}^{+}$into the $\mathrm{C}-\mathrm{F}$ bond. This insertion complex transforms then to $\mathrm{LnF}^{+}$producing the alkyl radical.

These two mechanisms were evidenced in several theoretical studies using mainly standard B3LYP computations [17-20]. Thus, Matsuda et al. have shown that the activation of C-F fluoromethane bond by lanthanide cations $\left(\mathrm{Ln}^{+}\right)$proceeds according the 'harpoon' mechanism for $\mathrm{Ln}=\mathrm{Ce}, \mathrm{Nd}, \mathrm{Sm}, \mathrm{Gd}, \mathrm{Dy}, \mathrm{Er}$ and $\mathrm{Yb}$, whereas the 'insertion elimination' mechanism should be observed for $\mathrm{Ln}=\mathrm{Pr}, \mathrm{Pm}, \mathrm{Eu}, \mathrm{Tb}, \mathrm{Ho}$ and $\mathrm{Tm}$.

However, to our knowledge, compared to the activation of the strong bonds such $\mathrm{C}-\mathrm{C}, \mathrm{C}-\mathrm{H}$ of hydrocarbons, methane in particular by lanthanide ions, the reactivity of the gas-phase actinide monocations or actinide complexes towards the simplest hydrocarbon molecule and derivatives was not studied in depth; indeed, only Almeida et al. carried out a theoretical prediction on the dehydrogenation of methane in gas phase by various atoms or metal ions such $\mathrm{Nb}, \mathrm{Nb}^{+}, \mathrm{Nb}^{2+}$ [21], all $\mathrm{Ln}^{+}[12], \mathrm{Th} \mathrm{Th}^{+}$and $\mathrm{Th}^{2+}$ [4], $\mathrm{Ac}^{+}$and $\mathrm{Pu}^{+}$[14]. Nevertheless, the theoretical aspects of the reactivity of actinide monocation toward fluoromethane have not yet been approached.

With an aim of probing various aspects of the gas phase reactivity of actinide cations, we found therefore interesting to investigate theoretically the activation of $\mathrm{C}-\mathrm{F}$ bond of a fluorinated derivative of methane, i.e. $\mathrm{CH}_{3} \mathrm{~F}$, by actinide monocations $\mathrm{An}^{+}$( $\mathrm{An}=\mathrm{Ac}, \mathrm{Th}, \mathrm{Pa}$, $\mathrm{U}, \mathrm{Np}, \mathrm{Pu}$ and $\mathrm{Am}$ ) in order to evidence the ability of these bare monocations to react with fluorohydrocarbons, to investigate if differentiation between these ions occurs and to propose possible reaction mechanisms. One underlying reason of our investigation on the ability of different actinide ions to break strong bonds is its usefulness in the context of accidental radioactive contamination.

\section{Computational details}

Scalar relativistic Density Functional Theory (DFT) [22-24] calculations have been carried at the Zeroth Order Regular Approximation level (ZORA) [25-27] using the Amsterdam Density Functional (ADF2014.01) program package [28-30]. The Vosko-Wilk-Nusair functional (WVN) [31] for the local density approximation (LDA) and the gradient corrections for exchange and correlation of Becke and Perdew respectively, i.e. the BP86 
functional [32] have been used. Triple- $\zeta$ Slater-type valence orbitals (STO) augmented by one set of polarization functions (TZP) were used for all atoms. For all elements, the basis sets were taken from the ADF/ZORA/TZP database. The frozen-core approximation where the core density is obtained from four-component Dirac-Slater calculations has been applied for all atoms. 1s core electrons were frozen respectively for carbon C.1s and fluorine F.1s. The Ac.5d, Th.5d, U.5d, Pa.5d, Np.5d, Pu.5d and Am.5d valence space of the heavy element includes the $5 \mathrm{f} / 6 \mathrm{~s} / 6 \mathrm{p} / 6 \mathrm{~d} / 7 \mathrm{~s} / 7 \mathrm{p}$ shells (14 valence electrons). Several studies have shown that the ZORA/BP86/TZP approach reproduces the experimental geometries and ground states properties of $\mathrm{f}$-block element compounds with a satisfying accuracy [33-36]. Molecular geometries and molecular orbital plots were generated, respectively, by using the MOLEKEL [37] and ADFVIEW programs [30].

Spin-orbit corrections (SOC) to the energies of the reactants and all other states, i.e. intermediate, transition, products, have not been considered, since their effects should be similar for all species for a given actinide ion and spin state, and therefore should not affect the reaction profile [38]. Indeed, studies of catalytic reactions involving actinide ions or actinide molecular systems with methane showed that these SOC corrections have very little effect on their optimized geometries [38,39]; moreover, Michelini et al. studying the $\mathrm{H}_{2} \mathrm{O}$ dehydrogenation by actinide ions, concluded that the SOC at the DFT level generally decreases slightly the activation barriers whereas its effect on the bond dissociation energy is very small (less than $0.25 \mathrm{kcal} / \mathrm{mol})$ [39a,b].

In our work, the spin contamination of the species involved in $\mathrm{An}^{+}+\mathrm{CH}_{3} \mathrm{~F}$ reactions (reactants, IMs and TSs) will be checked; the DFT computed mean values of the square spin operator $\left\langle\mathrm{S}^{2}\right\rangle$ should be close to the exact $\mathrm{S}(\mathrm{S}+1)$ values. It is worth noting that Montoya and Truong [40c] showed that unrestricted DFT computations are useful tools to investigate chemical reactions due to the small spin contamination that they exhibit.

All geometry optimizations were carried out without any symmetry constraint, at the spinunrestricted level of theory, considering the molecular systems in the gas-phase, which is the usual experimental medium of such studies. All obtained stationary points located on the PES were characterized as extrema which could be intermediate states (IM) without any imaginary frequency (Nimag=0) or first order transition states (TS) with only one imaginary frequency (Nimag=1, see SI) through harmonic approximation vibrational frequency calculations. The zero-point vibrational energy (ZPVE) corrections were calculated and included in all reported relative energies, obtained for a temperature of $298.15 \mathrm{~K}$. The intrinsic reaction coordinate 
(IRC) method [41] was used to confirm the transition states linking the two corresponding minima (intermediates states or final products). The Hirshfeld [42] electronic charge analysis has been used to characterize the charge transfer during the chemical reaction.

In terms of the energies at optimized geometries, the activation barrier $\Delta \mathrm{G}$ were computed as differences of total energies like:

$\Delta \mathrm{G}=\Delta \mathrm{G}(\mathrm{TS})-\Delta \mathrm{G}\left(\mathrm{IM}_{1}\right)$

Where $\Delta \mathrm{G}(\mathrm{TS})$ corresponds to the transition state Gibbs free energy, and $\Delta \mathrm{G}\left(\mathrm{IM}_{1}\right)$ is the Gibbs free energy of the first intermediate state of the reaction. It is reminded that the ADF program computes the Total Bonding Energies (TBE) of the considered species and not their energies.

\section{Results and discussion}

\subsection{Stationary points geometries and energies}

Thanks to linear transit (LT) calculations, the stationary points on the PES were identified and their corresponding structures optimized. By mean of intrinsic reaction coordinate (IRC) calculations, we made sure that the obtained transition states connect their corresponding minima.

First we present the optimized geometries of the species $\mathrm{CH}_{3} \mathrm{~F}$ and $\mathrm{CH}_{3}$, depicted in Fig. 1, as well as their corresponding calculated vibration frequencies given in Table 1.

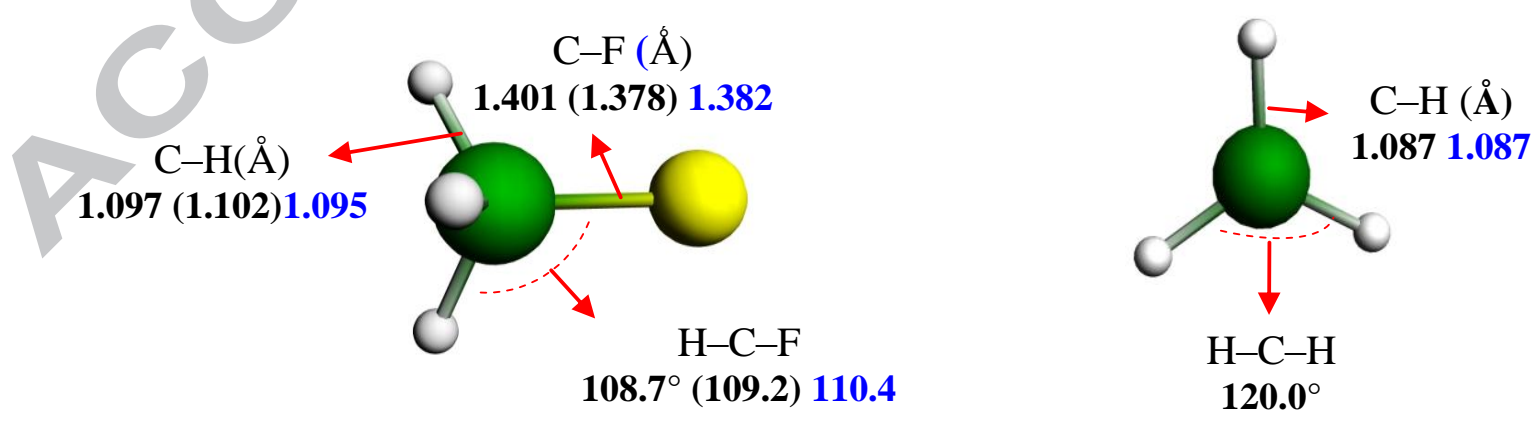

Fig. 1. Optimized geometries of fluoromethane $\mathrm{CH}_{3} \mathrm{~F}$ and the $\mathrm{CH}_{3}$ radical. Experimental data (values in blue-bold) [43]. Previous theoretical calculations in parentheses [17]. 
As it can be seen in Table 1, the computed bond lengths and vibration frequencies are in good agreement with experiment [43] and with the previous theoretical calculations of Zhang et al. [18].

Table 1. Calculated vibration frequencies of $\mathrm{CH}_{3} \mathrm{~F}$ and $\mathrm{CH}_{3}$, experimental values in blue bold and previous theoretical values [18] in parentheses.

\begin{tabular}{cccccc}
\hline Freq $\left(\mathrm{cm}^{-1}\right)$ & $\mathbf{C H}_{\mathbf{3}} \mathbf{F}$ & & $\mathbf{C H}_{\mathbf{3}}$ & \\
\cline { 1 - 2 } $\mathbf{1}$ & $1012(1081) \mathbf{1 0 4 9}$ & & $542(608)$ & $\mathbf{5 8 0}$ \\
$\mathbf{2}$ & $1145(1151) \mathbf{1 1 8 2}^{\mathbf{a}}$ & & $1358(1337)^{\mathbf{a}}$ & $\mathbf{1 3 8 3}$ \\
$\mathbf{3}$ & $1427(1424) \mathbf{1 4 6 4}^{\mathbf{a}}$ & & $3017(3059)$ & $\mathbf{3 0 0 2}$ \\
$\mathbf{4}$ & $1444(1426) \mathbf{1 4 6 4}^{\mathbf{a}}$ & & $3210(3253)^{\mathbf{a}}$ & $\mathbf{3 1 8 4}$ \\
$\mathbf{5}$ & $2949(2974) \mathbf{2 9 3 8}$ & & & \\
$\mathbf{6}$ & $3050(3068) \mathbf{3 0 0 6}^{\mathbf{a}}$ & & \\
\hline
\end{tabular}

adoubly degenerate mode

At the very beginning, in order to compare our methodology to those of Zhang [18] and Almeida [4] who used DFT/B3LYP computations, we carried out the study of the reactivity of the lanthanide cation $\mathrm{Yb}^{+}$with the fluorinated hydrocarbon $\mathrm{CH}_{3} \mathrm{~F}$ and that of the actinide cation $\mathrm{Th}^{+}$with methane $\mathrm{CH}_{4}$.

The intermediate IM1, transition state and product optimized geometries are reported in Fig. 2 (Fig. 2a for the $\mathrm{Yb}^{+}+\mathrm{CH}_{3} \mathrm{~F}$ reaction and Fig. 2b for the $\mathrm{Th}^{+}+\mathrm{CH}_{4}$ one) with their corresponding relative electronic energies (total bond energy) including zero point vibration energy corrections.

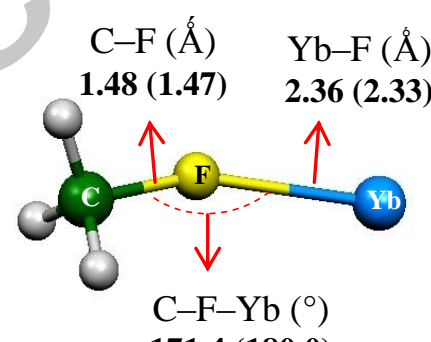

$171.4(\mathbf{1 8 0 . 0})$

TBE $(\mathrm{kcal} / \mathrm{mol})$

-19.63 (-19.86)

IM1

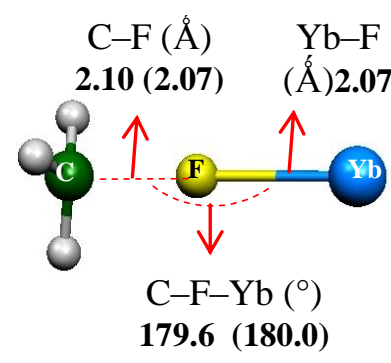

TBE (kcal/mol) -11.56 (-10.84)

TS

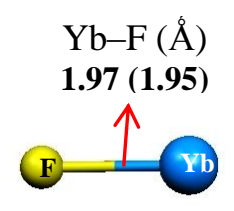

TBE (kcal/mol) -12.16 (-11.55)

Product YbF ${ }^{+}$ 
Fig. 2a. Ground state optimized geometries of stationary points of the $\mathrm{Yb}^{+}+\mathrm{CH}_{3} \mathrm{~F}$ reaction with their TBE in $\mathrm{kcal} / \mathrm{mol}$. The bond lengths are in angstroms and the angles are in degrees. Zhang's values between parentheses.
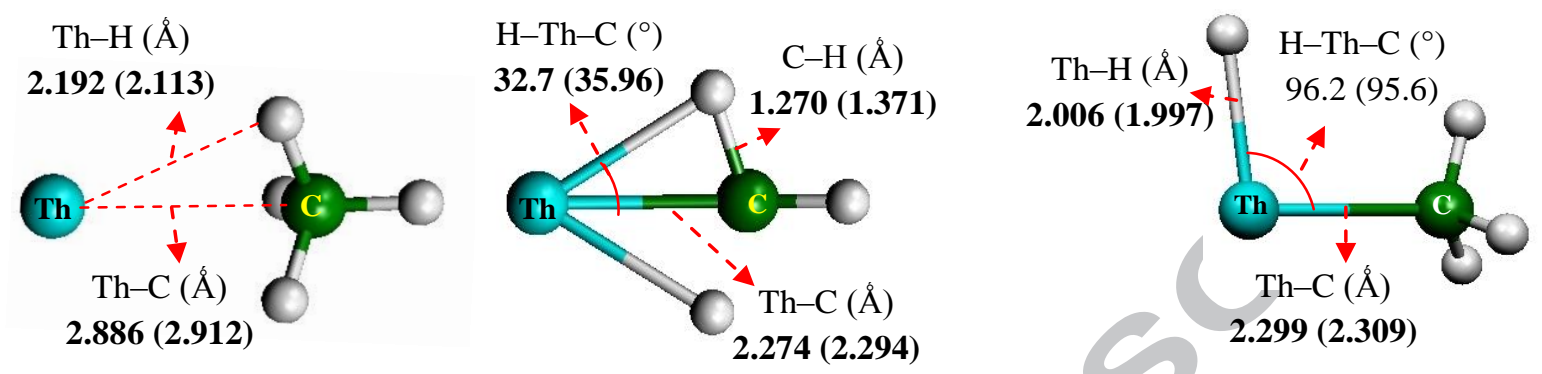

Activation barrier, computed as $\Delta \mathrm{E}=\mathrm{E}(\mathrm{IM} 1)-\mathrm{E}(\mathrm{TS})=1.72(2.21) \mathrm{kcal} / \mathrm{mol}$

IM1

TS

Product HThCH3 ${ }^{+}$

Fig. 2b. Ground state optimized geometries of stationary points of the $\mathrm{Th}^{+}+\mathrm{CH}_{4}$ reaction with its activation barrier in $\mathrm{kcal} / \mathrm{mol}$. The bond lengths are in angstroms and the angles are in degrees. Almeida's values between parentheses.

As it can be seen in Fig. 2a and 2b, our computed geometrical parameters as well as relative energies are found in good agreement with those found by Zhang [18] and Almeida [4] which are given in parentheses, denoting no contradiction between both computational methods.

In the present work, being interested in the reactivity of actinide cations, we carried out LT (Linear Transit) calculations for the reactions between $\mathrm{An}^{+}$monocations $(\mathrm{An}=\mathrm{Ac}, \mathrm{Th}, \mathrm{Pa}, \mathrm{U}$, $\mathrm{Np}, \mathrm{Pu}$ and $\mathrm{Am}$ ) and the fluorinated hydrocarbon $\mathrm{CH}_{3} \mathrm{~F}$, using the methodology described above based on ZORA/BP86/TZP calculations. The considered reaction coordinate is the distance between the $\mathrm{An}^{+}$cation and the fluorine atom of fluoromethane. For a good description of the mechanisms occurring during these C-F bond activation reactions by the actinide monocations, it is important to consider the different possible spin states of the reacting actinide monocations. Moreover, since we deal generally with open-shell systems, it is necessary to check that no spin contamination occurs at each step of the processes.

The ground state spin multiplicity of the considered actinide monocations is 1 for $\mathrm{Ac}^{+}$(this singlet state was found more stable than the triplet one), 4 for $\mathrm{Th}^{+}$(this quartet state is found 
more stable than the doublet one), 3 for $\mathrm{Pa}^{+}, 4$ for $\mathrm{U}^{+}, 5$ for $\mathrm{Np}^{+}, 6$ for $\mathrm{Pu}^{+}$and 7 for $\mathrm{Am}^{+}$. Except the $\mathrm{Ac}^{+}$case, the ground state corresponds generally to the higher spin state one. At the very beginning, it is worth noting that we found no spin contamination for any state in the case of ground state reactions.

Our obtained results show that the studied actinide monocations can be classified in two groups according to the $\mathrm{CH}_{3} \mathrm{~F}+\mathrm{An}^{+}$reaction paths they follow. In the first one are $\mathrm{Ac}^{+}, \mathrm{Pu}^{+}$ and $\mathrm{Am}^{+}$, and in the second one $\mathrm{Th}^{+}, \mathrm{Pa}^{+}, \mathrm{U}^{+}$and $\mathrm{Np}^{+}$. The geometries of the intermediate states (IM) and transition states (TS) are shown in Tables 2 for the first group and 3 for the second one, with their total bonding energies (TBE) and relevant geometrical parameters. A very significant fact to note is that, except for the $\mathrm{Ac}^{+}$system, the geometries of the IM, TS with different spin states are similar with very small variations of the geometrical parameters. The coordinates of all molecular structures are given in the Supporting Information (SI).

The first group (Table 2) is characterized by the presence of one intermediate state IM1 and the transition state geometries are close to linear structure. In this group, the reaction of $\mathrm{Pu}^{+}$, $\mathrm{Am}^{+}$and $\mathrm{Ac}^{+}$(triplet), with $\mathrm{CH}_{3} \mathrm{~F}$ is initiated by an electrostatic attraction between the cation and the negative fluorine atom leading to the formation of an intermediate ion complex $\mathrm{IM}_{1}$ $\left(\mathrm{CH}_{3} \mathrm{~F}-\mathrm{An}^{+}, \mathrm{An}=\mathrm{Pu}\right.$ and $\left.\mathrm{Am}\right)$ with a TBE of $-523.1 \mathrm{kcal} / \mathrm{mol}$ for the $\mathrm{Pu}^{+}$system, -559.4 $\mathrm{kcal} / \mathrm{mol}$ for the $\mathrm{Am}^{+}$system and $-437.4 \mathrm{kcal} / \mathrm{mol}$ for the $\mathrm{Ac}^{+}$(triplet) one their relative energies with respect to reactants are $-28.1,-16.3$ and $-26.3 \mathrm{kcal} / \mathrm{mol}$ respectively, which indicates the strong stabilizing electrostatic interaction between $\mathrm{An}^{+}$and $\mathrm{CH}_{3} \mathrm{~F}$.

Table 2. Optimized molecular structures of stationary points of the $\mathrm{An}^{+}+\mathrm{CH}_{3} \mathrm{~F}$ reaction $\left(\mathrm{An}^{+}\right.$ $=\mathrm{Ac}^{+}$(triplet), $\mathrm{Pu}^{+}, \mathrm{Am}^{+}$) with their corresponding total bonding energies (values in bold blue, in $\mathrm{kcal} / \mathrm{mol}$ ). Bond lengths are in angstroms and angles are in degrees. Spin multiplicity between square brackets.

\begin{tabular}{|l|llll|}
\hline An & IM1 & TS & IM2 & AnF $^{+}$ \\
\hline
\end{tabular}




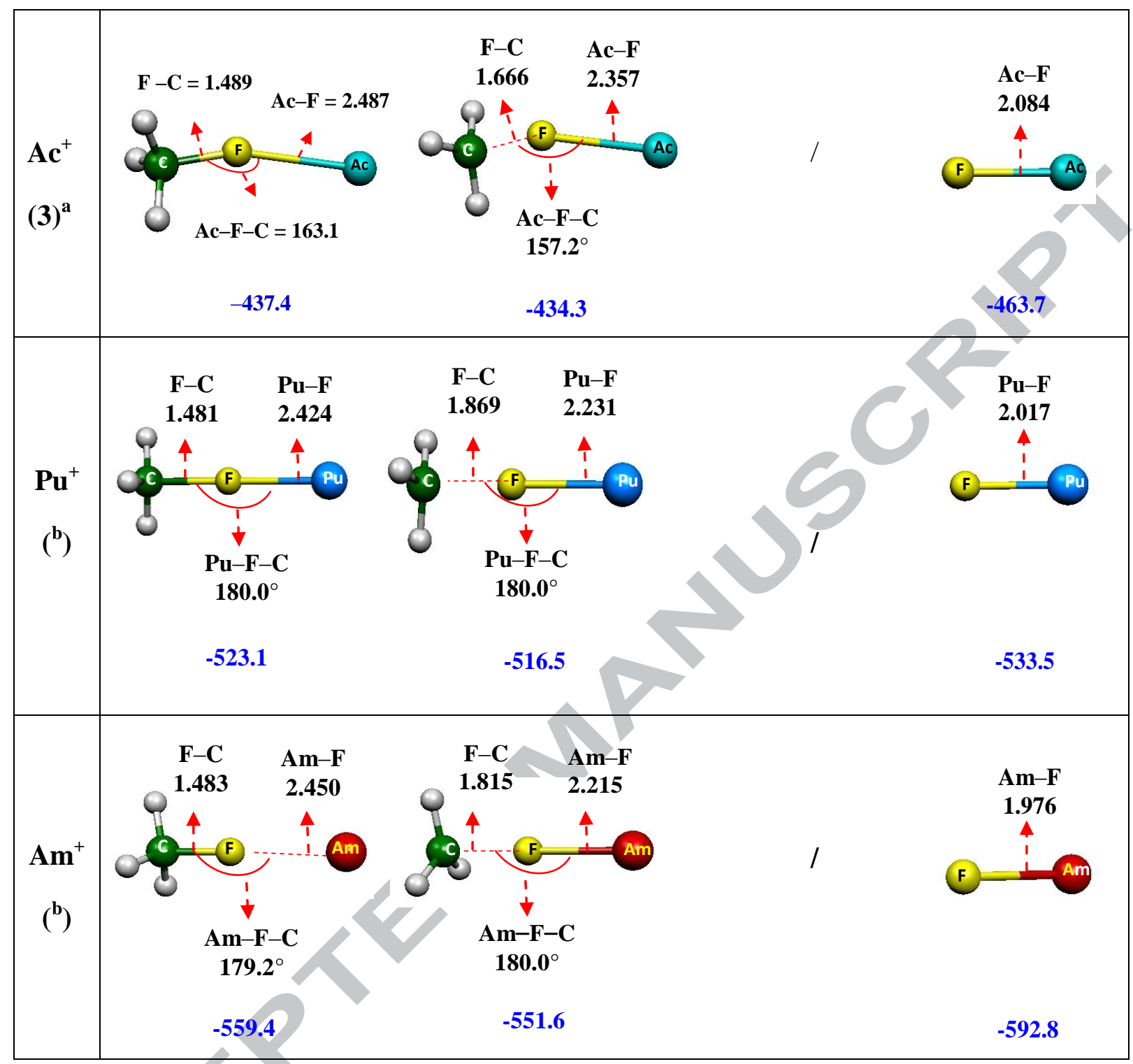

atriplet state of $\mathrm{Ac}^{+}$; ${ }^{\mathrm{b}}$ Similar geometries for all spin multiplicities, 7 and 9 for $\mathrm{Am}^{+}$, and 6 and 8 for $\mathrm{Pu}^{+}$.

The computed $\mathrm{C}-\mathrm{F}$ bond length and the $\mathrm{H}-\mathrm{C}-\mathrm{H}$ angle of the first intermediate state $(1.481 \AA$, $112.3^{\circ}$ for the Pu system, $1.483 \AA, 113.4^{\circ}$ for the Am system) are very close to $1.401 \AA$ and $109.5^{\circ}$ in the free $\mathrm{CH}_{3} \mathrm{~F}$. The calculated $\mathrm{An}-\mathrm{F}$ bond lengths in the two IM1 states $(\mathrm{An}=\mathrm{Pu}$, Am) are found to be $2.424 \AA$ and $2.450 \AA$ while the $\mathrm{C}-\mathrm{F}-\mathrm{An}$ angles are close to $180^{\circ}$, thus confirming the linear conformation of these intermediate structures. These structural results obtained for actinide ions suitably reproduce those of their lanthanide counterparts given by experiments or by theoretical computations $[16,18]$.

The transition states of these two reactions present a linear $\mathrm{C}-\mathrm{F}-\mathrm{An}$ structure similar to that found in the case of the lanthanide monocations $\left(\mathrm{Ce}^{+}, \mathrm{Nd}^{+}, \mathrm{Sm}^{+}, \mathrm{Gd}^{+}, \mathrm{Dy}^{+}\right.$and $\left.\mathrm{Er}^{+}\right)$when 
reacting with $\mathrm{CH}_{3} \mathrm{~F}$ [18]; the bond lengths of $\mathrm{Pu}-\mathrm{F}$ and $\mathrm{Am}-\mathrm{F}$ are respectively equal to 2.231 Á and $2.215 \AA$ in the TS.

The IRC calculations carried out for the $\mathrm{CH}_{3} \mathrm{~F}-\mathrm{An}^{+}$systems $\left(\mathrm{An}^{+}=\mathrm{Ac}+(\right.$ triplet $\left.), \mathrm{Pu}^{+}, \mathrm{Am}^{+}\right)$ showed the nonexistence of an intermediate state IM2 between the TS and the products; the latter ones are directly connected to form the product $\mathrm{AnF}^{+}$. We note that in the three reactions, independently of the considered spin state, the TS and products are more stable than the reactants, as can be seen on the energy profiles of the representative $\mathrm{CH}_{3} \mathrm{~F}+\mathrm{Am}^{+}$reaction in Fig. 3a, where the Gibbs free energies relative to the reactants of $\mathrm{Am}^{+}$nonet ground state obtained at $298.15^{\circ} \mathrm{K}$ are given. Only the ground state and the low-lying excited states of the $\mathrm{Am}^{+}$cation were represented in these diagrams, i.e. the nonet (spin multiplicity 9), the septet state (7); the singlet state $\mathrm{Am}^{+}(1)$ is too high in energy to be included in these diagrams whereas the quintet (5) and the triplet state (3) led to important spin contamination in the IM1 and TS and cannot be studied at the used level of theory. The differences between the geometries of the septet and the nonet states are small.

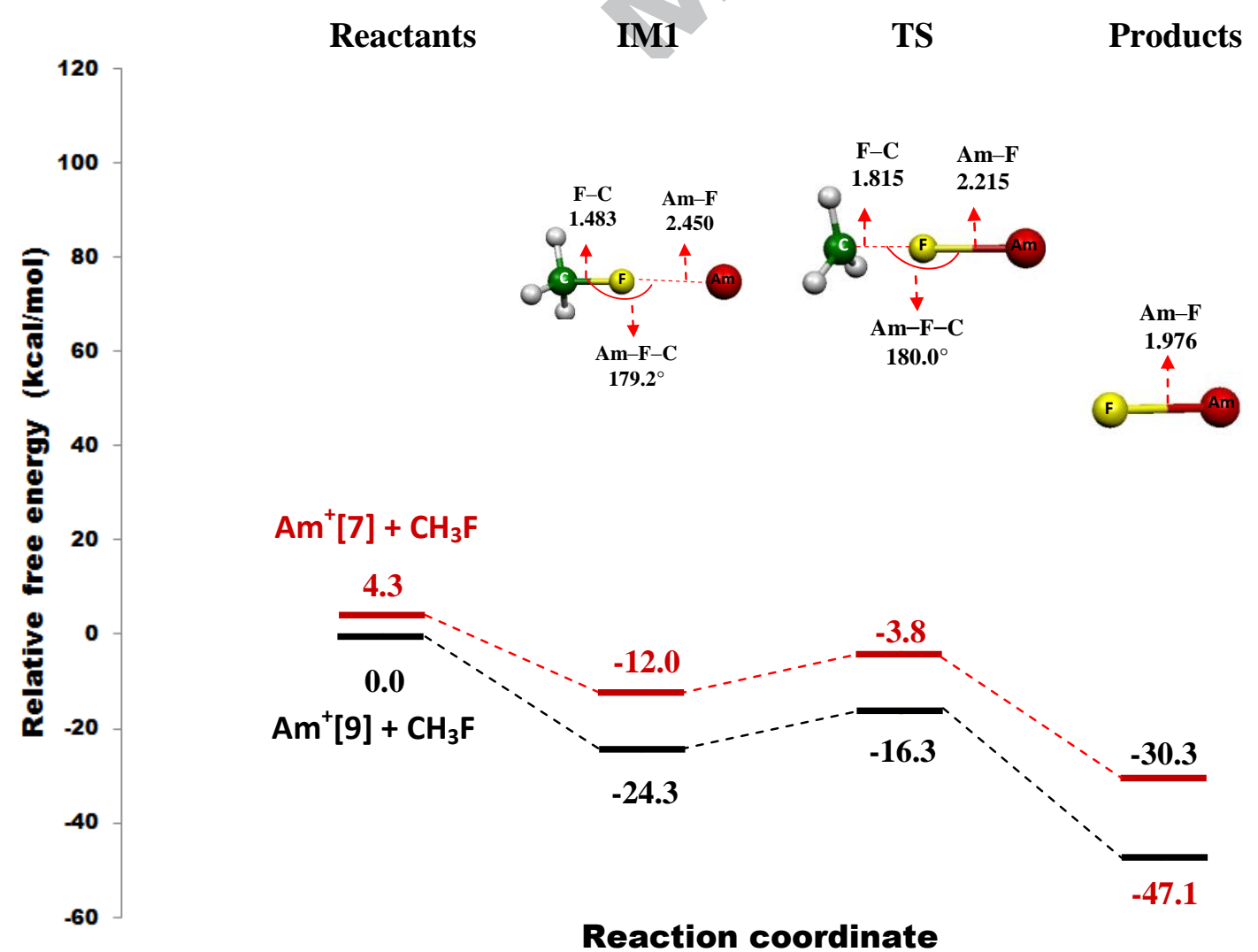

Fig. 3a. Potential energy profiles of the $\mathrm{CH}_{3} \mathrm{~F}+\mathrm{Am}^{+}$reaction (distances in $\AA$ ). The different spin multiplicities are given in square brackets. 
Contrarily to the $\mathrm{Pu}^{+}$and $\mathrm{Am}^{+}$cases, the reaction of $\mathrm{CH}_{3} \mathrm{~F}$ with $\mathrm{Ac}^{+}$in the triplet state (the singlet one will be discussed later in the text) shows a transition state which does not exhibit a linear $\mathrm{C}-\mathrm{F}-\mathrm{Ac}$ structure. As it can be seen in Table 2, the $\mathrm{C}-\mathrm{F}-\mathrm{Ac}$ angle is estimated to be $157.2^{\circ}$ and the Ac-F bond length $(2.357 \AA)$ is longer than that of IM1 of the previous $\mathrm{Pu}^{+}$and $\mathrm{Am}^{+}$cases. If we compare the geometrical parameters of the transitions states of the three complexes, we note that $\mathrm{Ac}^{+}$presents the largest $\mathrm{An}-\mathrm{C}$ bond length, in line with the fact that the ionic radius of $\mathrm{Ac}^{+}$is larger than those of $\mathrm{Pu}^{+}$and $\mathrm{Am}^{+}$about $0.2 \AA$ [44], and the smallest $\mathrm{F}-\mathrm{C}$ one thus leading to a non-linear $\mathrm{C}-\mathrm{F}-\mathrm{Ac}$ structure. Even if the $\mathrm{C}-\mathrm{F}-\mathrm{Ac}$ angle increases when reaching the IM2, the $\mathrm{C}-\mathrm{F}-\mathrm{Ac}$ structure tends to linearity, but was not entirely linear, with an angle of $163.6^{\circ}$.

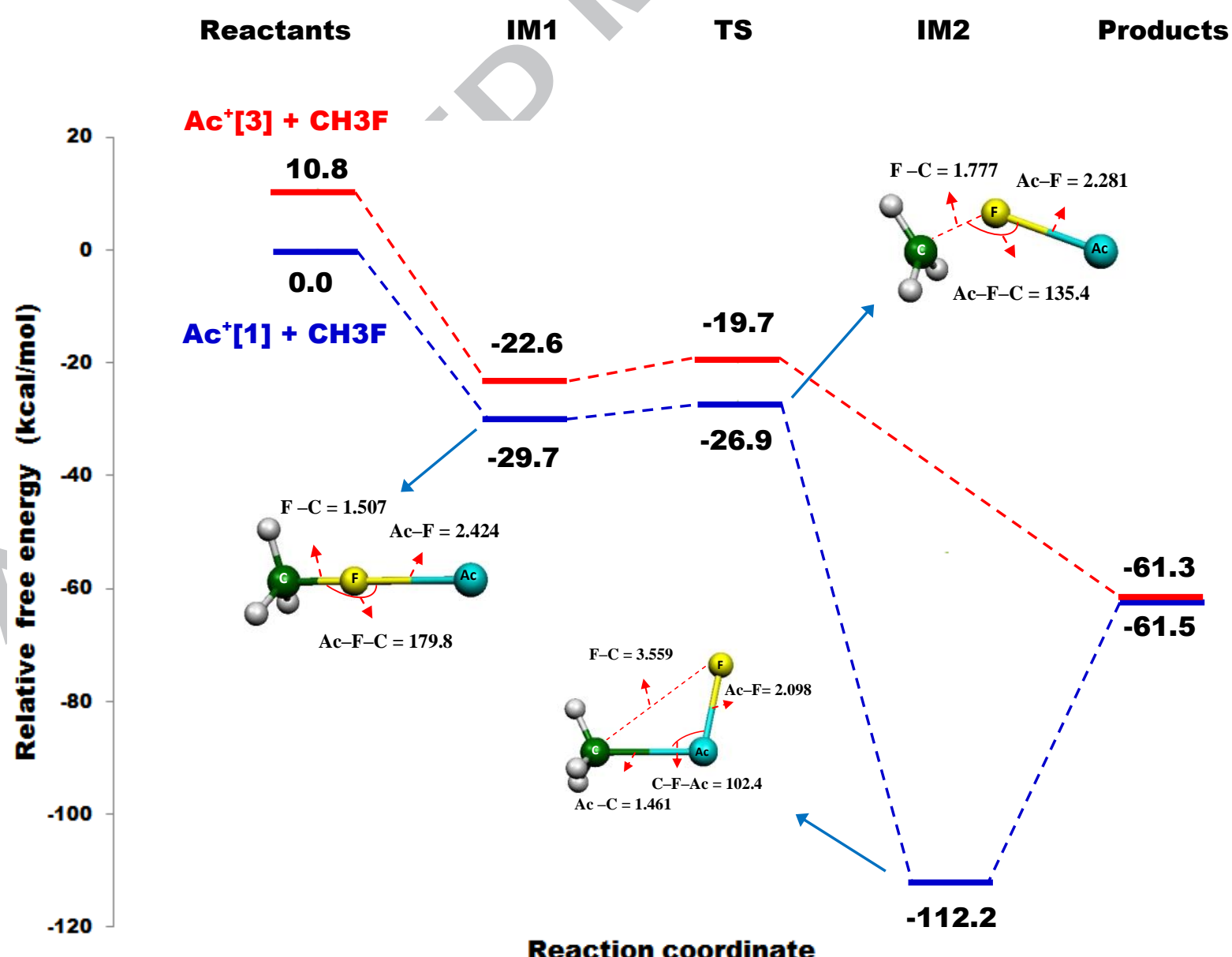


Fig. 3b. Potential energy profiles of the $\mathrm{CH}_{3} \mathrm{~F}+\mathrm{Ac}^{+}$reaction in the triplet and singlet states (spin multiplicities in square brackets). The structures displayed are those of the singlet spin state.

The second group of actinide ions reacting with $\mathrm{CH}_{3} \mathrm{~F}$ is composed of $\mathrm{Th}^{+}, \mathrm{Pa}^{+}, \mathrm{U}^{+}$and $\mathrm{Np}^{+}$ and $\mathrm{Ac}^{+}$in its singlet state. Here, in all reactions and for all considered ground spin states, the transition state connects intermediate states IM1 and IM2, as evidenced by the IRC calculations. Except the linear IM1 in the case of the singlet Ac system, all intermediates and transition structures exhibit bent geometries (see Table 3 and Fig. 3b), contrarily to those observed for the first group of actinide ions. At the TS, the C-F bond starts to break according to the lengthening of its bond length whereas the F-An bond starts to be formed. In Table 3, are displayed the optimized molecular structures of the $\mathrm{An}^{+}+\mathrm{CH}_{3} \mathrm{~F}$ reaction $(\mathrm{An}=\mathrm{Th}, \mathrm{Pa}, \mathrm{U}$ and $\mathrm{Np}$ ). Relevant geometrical parameters are given for all the species involved in these reactions, with their corresponding total bonding energies $(\mathrm{kcal} / \mathrm{mol})$. As one can see in this table, the IM1 states that connect the reactants and the TS present similar structures in all cases. The F-C and An-F bond lengths are close to $1.50 \AA$ and $2.37 \AA$ (within $0.02 \AA$ ) respectively while the $\mathrm{An}-\mathrm{F}-\mathrm{C}$ angles are close to $150^{\circ}$ (within $5^{\circ}$ ).

Table 3. Optimized molecular structures of stationary points of the $\mathrm{An}^{+}+\mathrm{CH}_{3} \mathrm{~F}$ reaction (An $=\mathrm{Th}, \mathrm{Pa}, \mathrm{U}$ and Np) with their corresponding TBE (values in bold blue, in $\mathrm{kcal} / \mathrm{mol}$ ). Bond lengths are in angstroms and angles are in degrees.

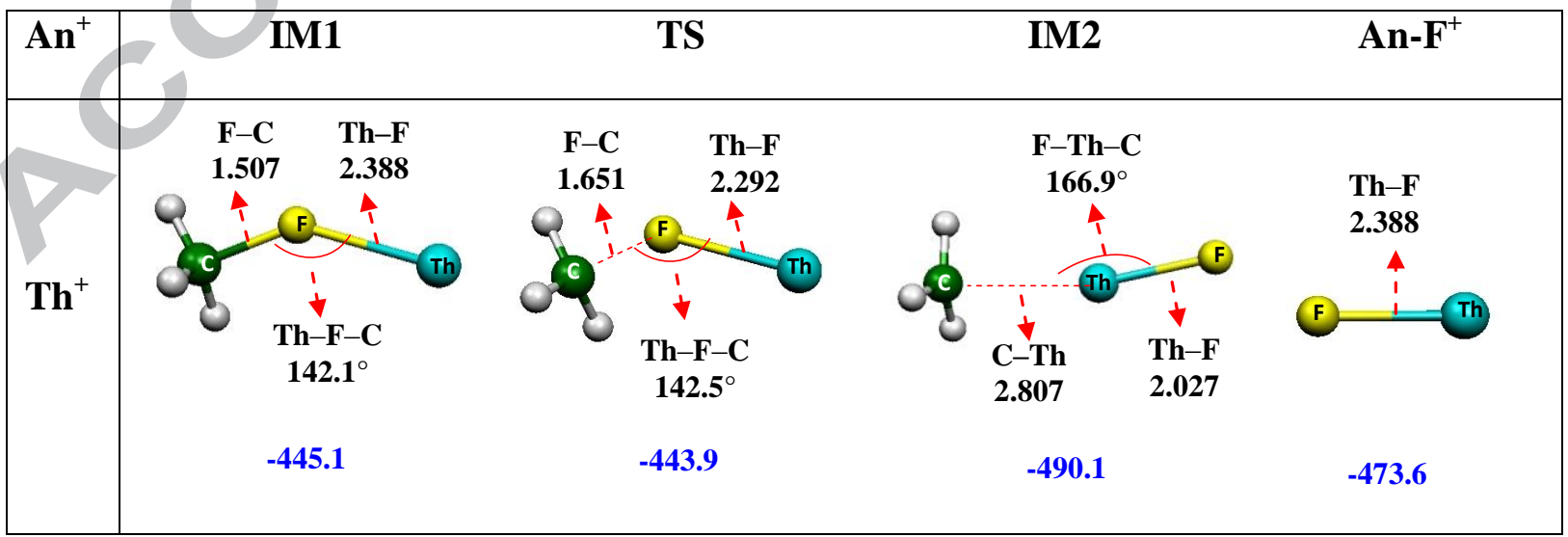




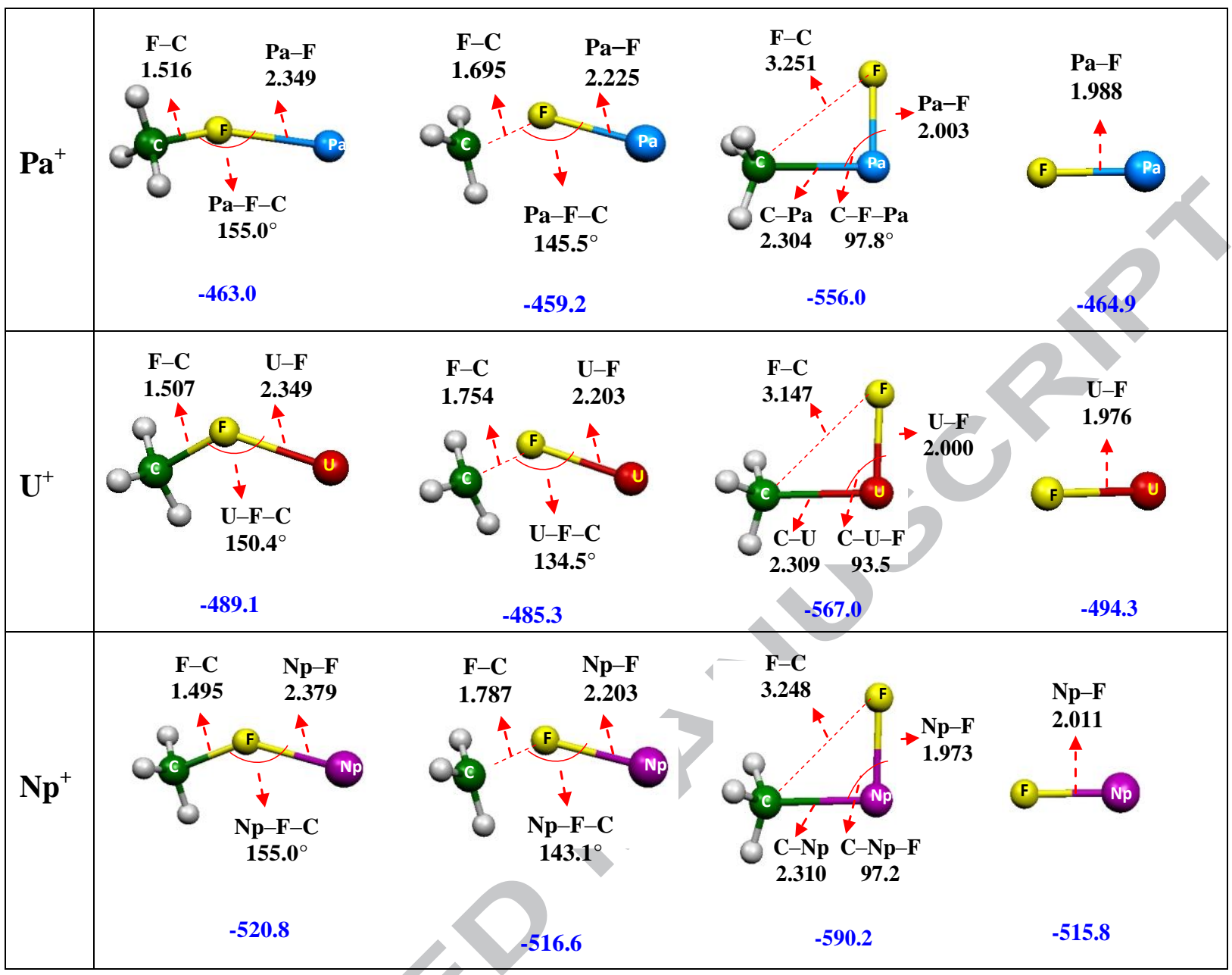

Contrarily to the first mechanism (Table 2), the TS(s) do not present $\mathrm{C}-\mathrm{F}-\mathrm{An}^{+}$linear structures. The corresponding $\mathrm{C}-\mathrm{F}-\mathrm{An}$ angles vary from $134.5^{\circ}$ for $\mathrm{U}^{+}+\mathrm{CH}_{3} \mathrm{~F}$ and $145.5^{\circ}$ for $\mathrm{Pa}^{+}+\mathrm{CH}_{3} \mathrm{~F}$. The $\mathrm{An}^{+}$ion and the $\mathrm{F}$ atom approach each other and the bond length $\mathrm{An}-\mathrm{F}$ decreases to reach a value close to $2.2 \AA$ in all TS structures. Apart from the $\mathrm{Th}^{+}$case where the $\mathrm{C}-\mathrm{F}-\mathrm{An}^{+}$angle reaches $166.9^{\circ}$, the other IM2 present also the same structure, exhibiting a smaller angle $\left(93.5-97.8^{\circ}\right)$; the $\mathrm{An}^{+}-\mathrm{F}$ bond length becomes smaller than that in the TS structures (2.00 $\AA$ in average) and the IM2 ion/complex formed is like an insertion-oxidative complex where, after the rupture of the $\mathrm{C}-\mathrm{F}$ bond, the actinide cation inserts between these $\mathrm{C}$ and $\mathrm{F}$ atoms and forms two $\mathrm{An}-\mathrm{F}$ and $\mathrm{An}-\mathrm{C}$ bonds; the actinide cation occupies a vertex of the triangle formed by the $\mathrm{C}, \mathrm{F}$ and An atoms, approximately an An-shaped right-angled triangle. In the case of the ( $\left.\mathrm{Th}-\mathrm{CH}_{3}-\mathrm{F}\right)$ system, the distance between $\mathrm{Th}$ and $\mathrm{C}$ atoms is 2.807 $\AA$, indicating the absence of bond between these two atoms, compared to the other systems where the An-C bond length is $2.30 \AA$. In the case of $\mathrm{Th}^{+}$, it is worth noting that when considering the excited doublet state, spin contamination occurs in the IM1 and TS, so that 
this excited state cannot be studied confidently at our level of theory. This situation was already observed by Mazzone et al. [39c] who studied the $\mathrm{Th}^{+}+\mathrm{OH}_{2}$ gas phase reaction.

Reactants

TS

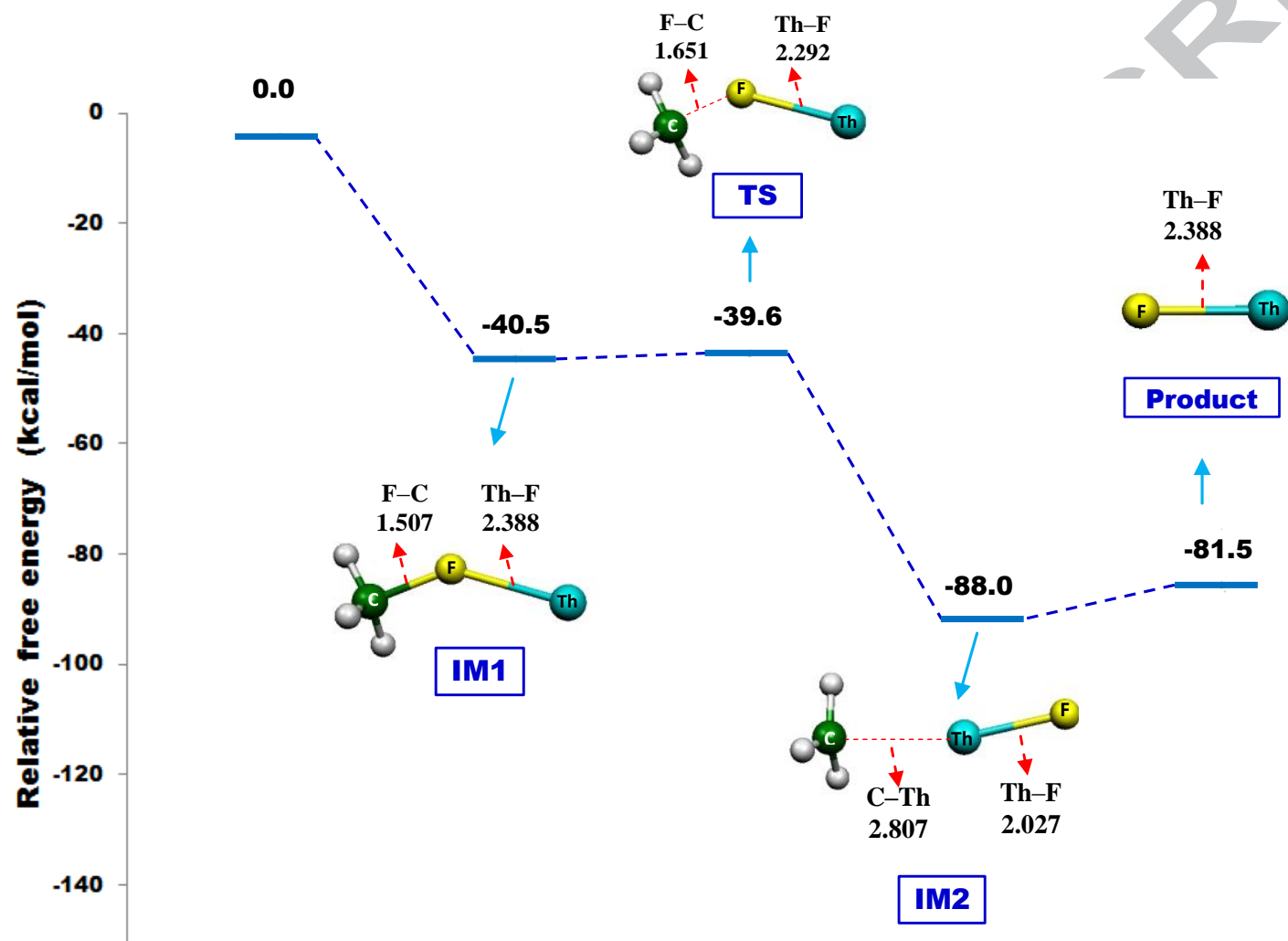

IM2

\section{Products}

Product

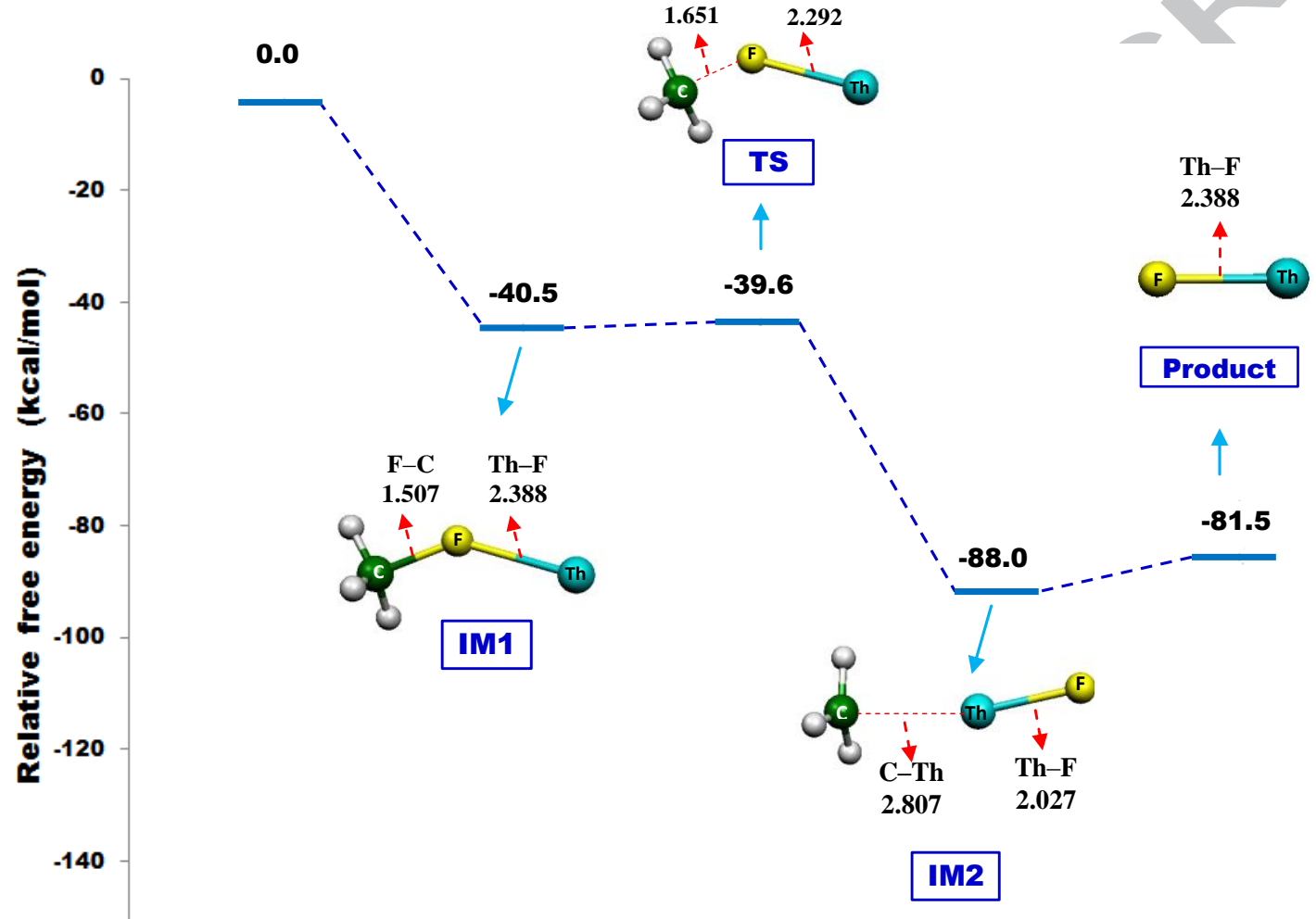

Reaction coordinate

Fig. 4. Potential energy profile of the $\mathrm{CH}_{3} \mathrm{~F}+\mathrm{Th}^{+}$reaction in the quartet spin state

At the end of the reaction, after the oxidative-insertion step, the product is formed by the elimination of the $\mathrm{CH}_{3}$ radical. The bond lengths of $\mathrm{An}-\mathrm{F}$ in the product vary from 1.976 to $2.388 \AA$, according to the ionic radii of the actinide ions. As shown in Fig. 4 which illustrates the energy diagram of the $\mathrm{Th}^{+}+\mathrm{CH}_{3} \mathrm{~F}$ reaction, for all other $\mathrm{An}^{+}$ions $(\mathrm{An}=\mathrm{Th}, \mathrm{Pa}, \mathrm{U}$ and Np) IM1, IM2 and final products are more stable than the reactants

Let us reconsider the atypical case of $\mathrm{Ac}^{+}$; the calculated structures and key geometrical parameters corresponding to the reaction intermediates and the transition states involved in 
the reaction in the singlet state are reported in Fig. 3b. These geometries are practically identical to that revealed in the group two $\left(\mathrm{Th}^{+}, \mathrm{Pa}^{+}, \mathrm{U}^{+}\right.$and $\left.\mathrm{Np}^{+}\right)$, implying thus that the suitable mechanism is the insertion-elimination one, in spite of the linear structure of its IM1. The bent geometries of the TS and IM2 are quite similar to those of the actinide cations involved in this mechanism.

\subsection{Reaction mechanisms}

In this section, we deal in-depth with the $\mathrm{An}^{+}+\mathrm{CH}_{3} \mathrm{~F}$ reaction processes involving the actinide monocations. We are faced to the $\mathrm{An}^{+}+\mathrm{CH}_{3} \mathrm{~F}$ reaction for which two mechanisms have been proposed, namely the 'harpoon mechanism' and the 'insertion-elimination mechanism'.

According to our results, the reactions of $\mathrm{Pu}$ and $\mathrm{Am}$ systems with fluoromethane show a similar mechanism. The $\mathrm{Am}^{+}$reaction mechanism (Fig. 3a) can be outlined as follows: the approach of the reactants is attractive, resulting in the formation of a stable ion-dipole IM1 complex, $\mathrm{An}^{+}-\mathrm{CH}_{3} \mathrm{~F}$. After this step, the most significant geometrical change is the lengthening of $\mathrm{C}-\mathrm{F}$ bond while, energetically, the intermediate complex lies below the ground state reactants. After the TS, where the C-F bond is broken, the actinide ion is bounded to the fluorine atom, leading to a linear actinide transition structure, this latter connecting IM1 and the products (the ionic species $\mathrm{AnF}^{+}$and the free radical $\mathrm{CH}_{3}$ ) without any intermediate IM2 between TS and products, as confirmed by IRC calculations.

An interesting result, shown in the computed reaction pathways of $\mathrm{Am}$ and $\mathrm{Pu}$ systems, displayed in Fig. 3a for Am (that of $\mathrm{Pu}$ is given in $\mathrm{SI}$ ), is that an intersystem crossing between the two lowest potential energy surfaces of each actinide ion $\mathrm{Am}^{+}$(nonet) and $\mathrm{Am}^{+}$(septet) could occur since the two surfaces are rather close in energy, thanks to spin-orbit coupling. Thus, for the Am system, the reaction should evolve mostly on the nonet ground state at any step of the reaction if initiated with the excited $\mathrm{Am}^{+}[7]$ state.

Moreover, the IM1 and TS geometries in the case of Pu and Am reactions present a linear structure as found by Matsuda group in the case of the reaction of lanthanide cations $\mathrm{Ln}^{+}, \mathrm{Ln}=$ $\mathrm{Yb}, \mathrm{Ce}, \mathrm{Nd}, \mathrm{Sm}, \mathrm{Gd}$, Dy and Er, with fluoromethane [13]; they concluded that the harpoon mechanism was the suitable one for this reaction. Accordingly, the activation of $\mathrm{C}-\mathrm{F}$ bond by $\mathrm{Pu}^{+}$and $\mathrm{Am}^{+}$proceeds as shown in scheme 1, denoting that the pure harpoon mechanism is the most suitable one to describe the reaction of $\mathrm{An}^{+}+\mathrm{CH}_{3} \mathrm{~F}$ with $\mathrm{An}=\mathrm{Pu}, \mathrm{Am}$. 
The other series of actinide cations exhibit a reaction pathway where the structures of the stationary points are close to the formal geometries defined in the insertion-elimination mechanism shown in scheme 2. In fact, according to our calculations, the three membered ring transition states, the three membered like reactant (IM1) and the product like intermediate $(\mathrm{IM} 2)$ of each actinide cation $\mathrm{An}^{+}(\mathrm{An}=\mathrm{Th}, \mathrm{Pa}, \mathrm{U}$ and $\mathrm{Np})$ systems were identified on the reaction pathway. After the TS formation, the oxidative-insertion process leads to the stable IM2 structure, followed by the elimination of the free radical $\mathrm{CH}_{3}$. For the actinium reaction, the potential energy surfaces corresponding to the singlet and triplet spin states, lead to final products identical in geometry and in energy (as shown in Fig. 3b). A transition from the triplet to the singlet ground state is possible due to spin-orbit coupling. If we analyse the reaction pathway in the case of $\mathrm{Ac}^{+}$in its triplet state we note the presence of IMs and TS which are different from the two formal reaction mechanisms defined in schemes 1 and 2. Wang and co-workers [19] defined the 'harpoon-like mechanism' for the reaction $\mathrm{La}^{+}$ $+\mathrm{CH}_{3} \mathrm{~F}$, in which the product-like intermediate IM2 is found on the reaction pathway as given in scheme 3:

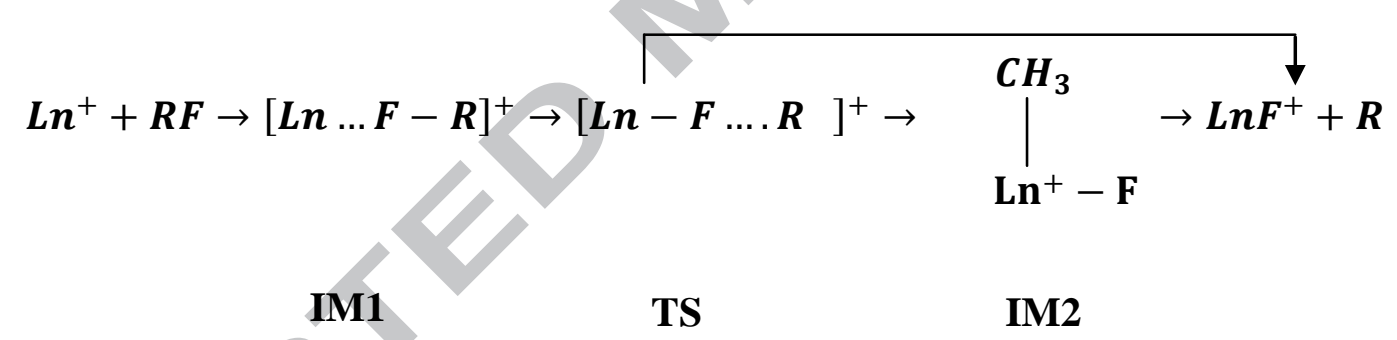

Scheme 3: 'Harpoon-like' reaction mechanism with an intermediate state

Thus, we conclude that the harpoon-like mechanism is the more appropriate to describe the triplet $\mathrm{Ac}^{+}$system.

Finally, considering the Table 4 where the energies of the stationary points for the ground states of the actinide cations are summarized, it can be seen that all the reactions are exergonic. 
Table 4. Gibbs energies of ground state stationary points: Reactants, Intermediates, Transition States and Products (Values between parentheses are relative energies, given in $\mathrm{kcal} / \mathrm{mol}$ ). Spin multiplicities between square brackets.

\begin{tabular}{|c|c|c|c|c|c|c|}
\hline \multicolumn{6}{|c|}{ Gibbs energy } & \multirow{2}{*}{$\begin{array}{l}\text { Activation } \\
\text { barrier } \Delta \mathbf{G}\end{array}$} \\
\hline An & Reactants & $\mathrm{IM}_{1}$ & TS & $\mathrm{IM}_{2}$ & Product & \\
\hline $\mathrm{Ac}[1]$ & $\begin{array}{c}-410.6 \\
(0)\end{array}$ & $\begin{array}{l}-440.3 \\
(-29.7)\end{array}$ & $\begin{array}{l}-437.5 \\
(-26.9) \\
\end{array}$ & $\begin{array}{l}-522.8 \\
-112.2\end{array}$ & $\begin{array}{l}-472.1 \\
(-61.5)\end{array}$ & 2.8 \\
\hline $\operatorname{Th}[4]$ & $\begin{array}{c}-400.3 \\
(0)\end{array}$ & $\begin{array}{l}-440.8 \\
(-40.5) \\
\end{array}$ & $\begin{array}{l}-439.8 \\
(-39.6) \\
\end{array}$ & $\begin{array}{l}-488.2 \\
(-88.0) \\
\end{array}$ & $\begin{array}{l}-481.8 \\
(-81.5) \\
\end{array}$ & 0.9 \\
\hline $\mathrm{Pa}[5]$ & $\begin{array}{c}-422.9 \\
(0)\end{array}$ & $\begin{array}{l}-456.0 \\
(-33.1)\end{array}$ & $\begin{array}{l}-453.9 \\
(-31.0)\end{array}$ & $\begin{array}{l}-502.4 \\
(-79.5)\end{array}$ & $\begin{array}{l}-495.1 \\
(-72.2)\end{array}$ & 2.1 \\
\hline $\mathrm{U}[4]$ & $\begin{array}{c}-443.5 \\
(0)\end{array}$ & $\begin{array}{l}-488.2 \\
(-44.7)\end{array}$ & $\begin{array}{l}-483.0 \\
(-43.1)\end{array}$ & $\begin{array}{c}-570.4 \\
(-126.9)\end{array}$ & $\begin{array}{r}-506.1 \\
(-62.6)\end{array}$ & 1.6 \\
\hline $\mathrm{Np}[7]$ & $\begin{array}{c}-499.2 \\
(0)\end{array}$ & $\begin{array}{l}-524.7 \\
(-25.5)\end{array}$ & $\begin{array}{l}-522.3 \\
(-23.1)\end{array}$ & $\begin{array}{r}-552.6 \\
(-53.4)\end{array}$ & $\begin{array}{l}-545.3 \\
(-46.1)\end{array}$ & 2.4 \\
\hline $\mathrm{Pu}[8]$ & $\begin{array}{c}-501.2 \\
(0)\end{array}$ & $\begin{array}{l}-530.3 \\
(-29.1)\end{array}$ & $\begin{array}{l}-525.3 \\
(-24.1) \\
\end{array}$ & 1 & $\begin{array}{l}-543.2 \\
(-42.0)\end{array}$ & 5.0 \\
\hline Am[9] & $\begin{array}{c}-543.6 \\
(0)\end{array}$ & $\begin{array}{l}-567.9 \\
(-24.3)\end{array}$ & $\begin{array}{l}-559.9 \\
(-16.3) \\
\end{array}$ & I & $\begin{array}{l}-573.9 \\
(-30.3)\end{array}$ & 8.0 \\
\hline
\end{tabular}

The reaction energies $\Delta \mathrm{G}^{0}$ vary from -81.5 for $\mathrm{Th}^{+}$to $-30.3 \mathrm{kcal} / \mathrm{mol}$ for $\mathrm{Am}^{+}$. The thorium cation system with a considerable exergonic character $(-81.5 \mathrm{kcal} / \mathrm{mol})$ and a very low activation barrier $(0.9 \mathrm{kcal} / \mathrm{mol})$ leads to an efficient reaction indicating the ability $\mathrm{of}^{+} \mathrm{Th}^{+}$to activate the fluoromethane $\mathrm{C}-\mathrm{F}$ bond compared to the other actinide cations in accordance with the study done by Almeida et al. [12] where they noted the efficiency of the $\mathrm{Th}^{+}$cation to activate the methane $\mathrm{C}-\mathrm{H}$ bond with an activation barrier of $1.3 \mathrm{kcal} / \mathrm{mol}$. Moreover, we note that these reactions are kinetically and thermodynamically favourable, and the activation energies which are low compared to those of lanthanide cations reacting with fluoromethane (-31.7 for $\mathrm{La}^{+},-27.2$ for $\mathrm{Ce}^{+},-22.8$ for $\mathrm{Pr}^{+}$and -19.9 for $\mathrm{Yb}^{+}$) [18,19] and, except for $\mathrm{Ac}^{+}$, increase with the atomic number of actinide cations.

With the activation barriers given in Table 4, we can classify the ability of actinide monocations to activate the $\mathrm{C}-\mathrm{F}$ bond of fluoromethane, in other words their reactivity, as follows: $\mathrm{Th}^{+} \geq \mathrm{U}^{+} \geq \mathrm{Pa}^{+} \geq \mathrm{Np}^{+}$for the first series concerned by the 'insertion-elimination' mechanism and $\mathrm{Ac}^{+}$(triplet) $>\mathrm{Pu}^{+}>\mathrm{Am}^{+}$for the second series in which the 'harpoon' mechanism occurs; these classifications are in agreement with the ordering of the second ionization energy (IE) of the actinide metal; a lower IE will lower the barrier and increase the 
reaction rate. These finding are consistent with the conclusion of the experimental study of Schwarz et al. [15].

\subsection{Mulliken populations, Hirshfeld Charges and Frontier MO analyses}

With the aim of a better understanding of the interactions between the actinide monocations and the $\mathrm{CH}_{3}-\mathrm{F}$ species, in particular the charge transfers occurring between these systems, two electron population analyses have been carried out, i.e. the Mulliken population analysis (MPA) and the Hirshfeld charge analysis (HA); the frontier molecular orbitals (FMO) were also considered. Although it has known drawbacks, MPA may indicate roughly the major charge transfers and bonding interactions when homologous series of molecules are compared. MPA metal spin populations (difference between the total $\alpha$ and $\beta$ electronic populations of the metal), MPA and HA net charges carried by the An metal, the fluorine atom and the $\mathrm{CH}_{3}$ moiety are given in Table 5 for three representative cases. Case A refers to $\mathrm{Ac}^{+}$in its triplet state which exhibits a 'harpoon-like' reaction mechanism with an intermediate, IM1, between reactants and TS, case $\mathrm{B}$ to $\mathrm{Pu}^{+}$cation concerned by the 'pureharpoon' reaction mechanism with an intermediate, IM1, between reactant and TS and finally case $\mathrm{C}$ to $\mathrm{U}^{+}$which leads to an insertion-elimination mechanism.

Table 5: MPA charges and spin populations of the species involved in the three reactions $\mathrm{An}^{+}$ $+\mathrm{CH}_{3} \mathrm{~F}\left(\mathrm{An}^{+}=\mathrm{Ac}+(\right.$ triplet $\left.), \mathrm{Pu}^{+}, \mathrm{Am}^{+}\right)$

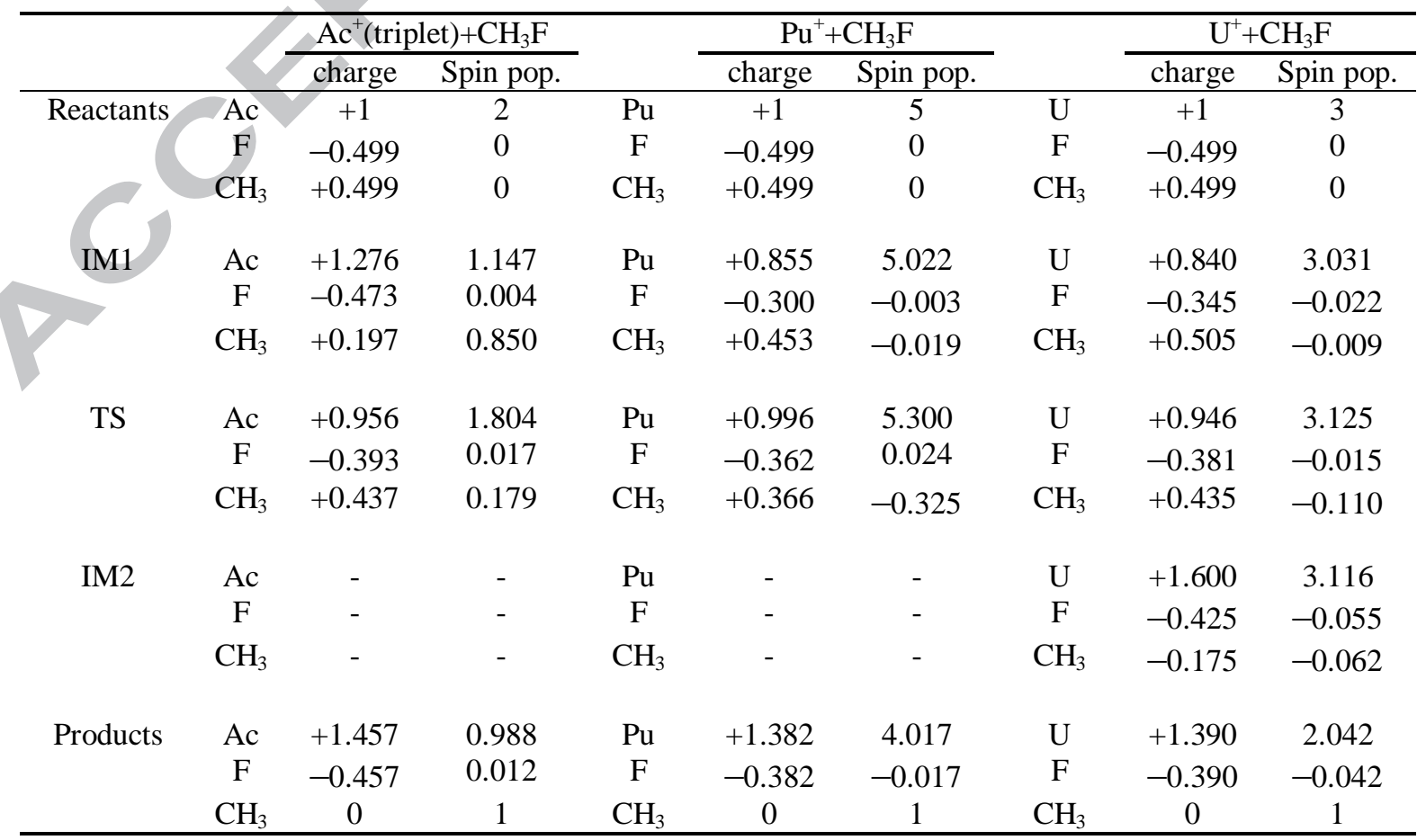


We discuss first the Mulliken population analysis (MPA); it can be seen for the intermediate state IM1, that the charge distributions and spin densities are 0.840 and 3.031 for $\mathrm{U}, 0.855$ and 5.022 for $\mathrm{Pu}$, and 1.276 and 1.147 for $\mathrm{Ac}(3)$ respectively. The results indicate that the unpaired electrons are mostly located on the metal ions in IM1s and that the interactions between $\mathrm{An}^{+}$and $\mathrm{CH}_{3} \mathrm{~F}$ are electrostatic in nature, as shown by the long $\mathrm{An}-\mathrm{F}$ bond distances (2.40 $\AA$ in average) and charge distribution. The MPA results indicated that, in the TS, the charges of $\mathrm{An}^{+}, \mathrm{F}$ and $\mathrm{CH}_{3}$ group are $+0.956,-0.393$ and +0.437 for the $\mathrm{Ac}(3)$ system, $+0.996,-0.362$ and +0.366 for the Pu one and $+0.946,-0.381$ and +0.435 for the $\mathrm{U}$ system. In IM1, the positive charge of the metal ion diminishes for the $\mathrm{Pu}^{+}$and $\mathrm{U}^{+}$ions, the fluorine atom losing a part of its initial negative charge, whereas the charge of the $\mathrm{CH}_{3}$ moiety remains constant in the case of the $\mathrm{U}$ system. On the contrary, the Ac charge increases when passing from reactants to IM1, from +1 to +1.276 whereas that of the $\mathrm{CH}_{3}$ decreases (from 0.499 to 0.197) indicating an electrostatic interaction between these entities being able to explain the non-linear structure of this IM1 state. In the TS, the metal charge is close to the initial value +1 , whereas in IM2 this charge increases significantly (to reach 1.600 for U). In the final state, the An- $\mathrm{F}^{+}$species exhibit charges in accordance with the relative electronegativities of the metal and the fluorine atom.

An alternative method to Mulliken charges is provided by Hirshfeld's analysis (HA), which is supposed to give more realistic net charges than MPA. The Hirshfeld atomic charges evolution during the reaction is reported in Fig. 5 for the representative case of an insertionelimination mechanism: that of the $\mathrm{U}^{+}+\mathrm{CH}_{3} \mathrm{~F}$ reaction. In this figure, are displayed the Hirshfeld net charges of the $\mathrm{CH}_{3}$ moiety, $\mathrm{U}$ and $\mathrm{F}$ atoms for all species involved in the reaction. As seen in this figure, the reaction of $\mathrm{U}^{+}$with fluorinated hydrocarbon can be understood as a simple charge transfer reaction starting from IM1, in which an electron is transferred from the atomic orbitals of $\mathrm{U}^{+}$to the $\sigma^{*} \mathrm{C}-\mathrm{F}$ orbital of $\mathrm{CH}_{3} \mathrm{~F}$ in this early stage $(\mathrm{IM} 1 \rightarrow \mathrm{TS})$ of the reaction.

In addition, the charge transfer in the case of $\mathrm{U}^{+}$which exhibits an insertion-elimination mechanism is found more important than that in the case of $\mathrm{Pu}^{+}$which has a harpoon mechanism (see Hirshfeld charges for all $\mathrm{An}^{+}+\mathrm{CH}_{3} \mathrm{~F}$ reactions in SI). Thus, the insertion elimination mechanism generally favours the charge transfer from $\mathrm{An}^{+}$to the $\sigma^{*}{ }_{\mathrm{C}}^{-\mathrm{F}}$ orbital as in the case of $\mathrm{Th}^{+}, \mathrm{Pa}^{+}, \mathrm{U}^{+}$and $\mathrm{Np}^{+}$systems. 


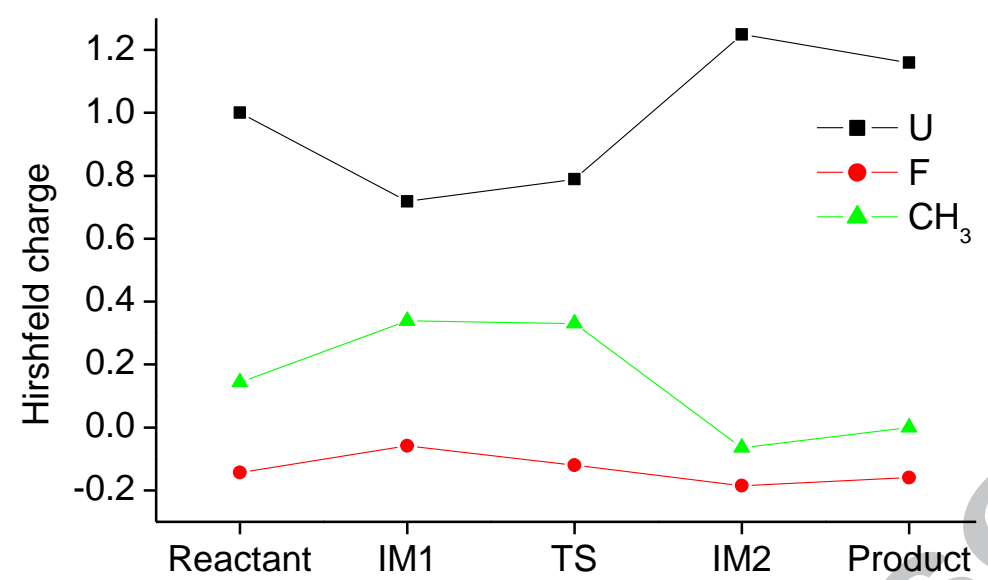

Fig. 5. $\mathrm{U}^{+}, \mathrm{F}$ and $\mathrm{CH}_{3}$ Hirshfeld charges evolution during the $\mathrm{U}^{+}+\mathrm{CH}_{3} \mathrm{~F}$ reaction

In order to understand and clarify the role of the frontier orbitals in the $\mathrm{C}-\mathrm{F}$ bond activation mechanism by actinide cations, the corresponding MO diagrams of the transition states are now considered. The computed energies of frontier orbitals, the singly occupied molecular orbital (SOMOs) and the lowest unoccupied molecular orbital (LUMOs) of the TS structures, are given in Table 6.

Table 6: Frontier molecular orbital energies $(\mathrm{eV})$ of the transition state structures

\begin{tabular}{cccccccc}
\hline Complex & $\mathrm{Ac}$ & $\mathrm{Th}$ & $\mathrm{Pa}$ & $\mathrm{U}$ & $\mathrm{Np}$ & $\mathrm{Pu}$ & $\mathrm{Am}$ \\
\hline SOMO & -7.274 & -8.094 & -8.259 & -8.632 & -8.536 & -8.320 & -8.923 \\
\hline LUMO & -7.197 & -7.967 & -8.157 & -8.232 & -8.357 & -8.167 & -7.903 \\
\hline Gap SOMO -LUMO & 0.077 & 0.127 & 0.102 & 0.400 & 0.179 & 0.153 & 1.020 \\
\hline
\end{tabular}

If all the SOMO and LUMO energies are negative, comprised between -7.197 and $-8.923 \mathrm{eV}$ as expected for cationic species, the values of the energy gap SOMO-LUMO, except for Am system, are very low (less than $0.4 \mathrm{eV}$ ) which is not surprising in the case of transition states. Interestingly, it can be seen that the SOMO and LUMO energies are ordered as $\mathrm{Ac}^{+}>\mathrm{Pu}^{+}>$ $\mathrm{Am}^{+}$for the ions giving the 'harpoon' mechanism and $\mathrm{Th}^{+}>\mathrm{Pa}^{+}>\mathrm{U}^{+}$for those of the 'insertion-elimination' one, except $\mathrm{Np}^{+} \mathrm{TS}$ structure which presents energies slightly higher than those of the $\mathrm{U}^{+}$system. 
Fig. 6 shows two frontier molecular orbitals of the transition states structures of all $\mathrm{An}^{+}+$ $\mathrm{CH}_{3} \mathrm{~F}$ reactions, namely the highest SOMO and the empty LUMO. The percentages $6 \mathrm{~d} / 5 \mathrm{f} / \mathrm{An} / \mathrm{CH}_{3} \mathrm{~F}$ indicate the weights of the $6 \mathrm{~d}$ and $5 \mathrm{f}$ metal orbitals as well as those of the actinide atom and of the $\mathrm{CH}_{3} \mathrm{~F}$ moiety in the MOs.

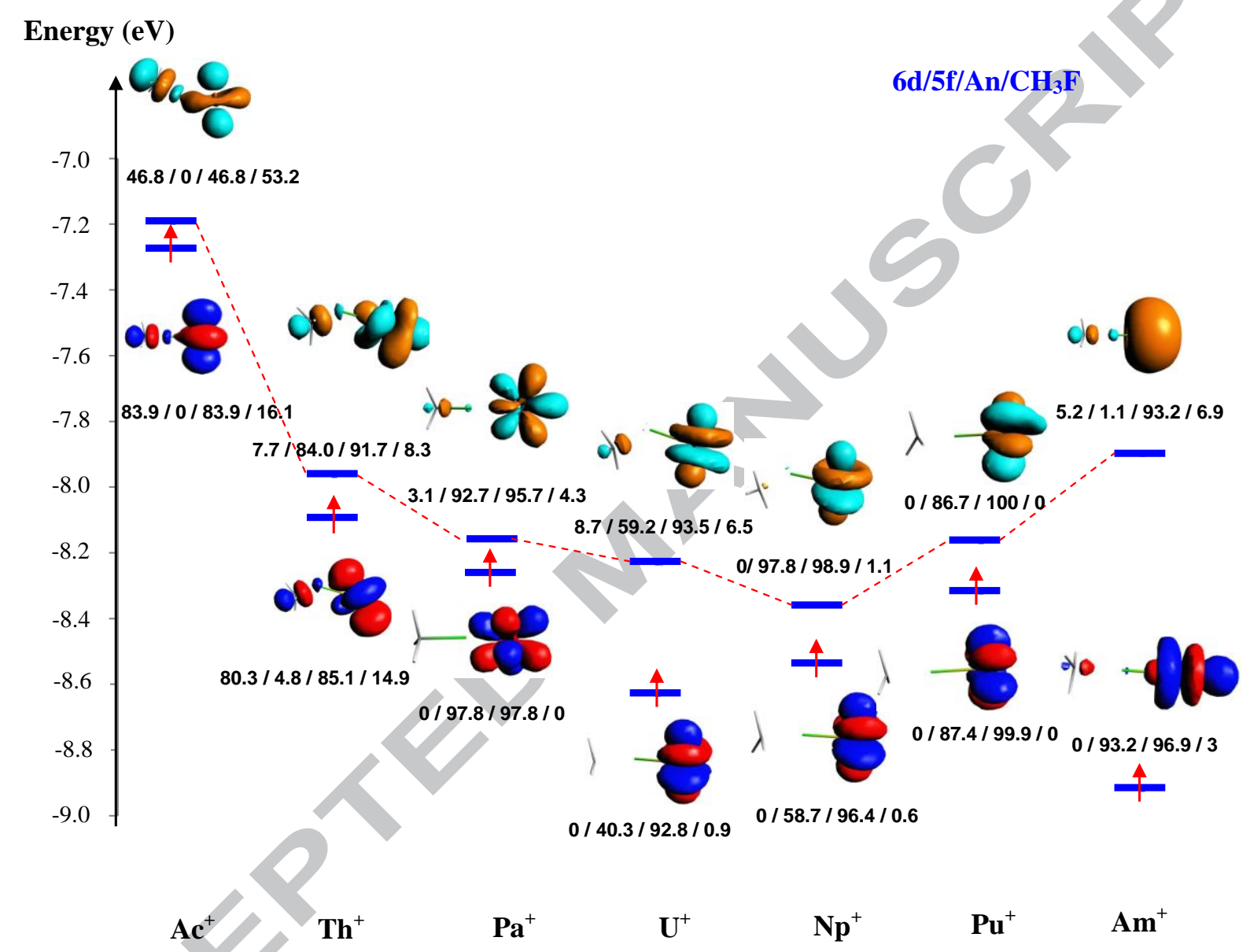

Fig. 6. Frontier molecular orbital diagrams of the TS structures

As one can see in this diagram, we observe that the SOMO for all TS structures exhibits an important metallic character, in line with the donating character of the metal centre. Interestingly, the orbital composition of these frontier MOs are different. In $\mathrm{Ac}^{+}$and $\mathrm{Th}^{+}$ systems, the main orbital component in SOMO is 6d with contribution of $83.9 \%$ and $80.3 \%$ respectively; in the others systems, the $5 f$ contribution is important, $40.3 \%$ for $\mathrm{U}^{+}, 58.7 \%$ for $\mathrm{Np}^{+}, 86.7 \%$ for $\mathrm{Pu}^{+}, 93.2 \%$ for $\mathrm{Am}^{+}$and $97.8 \%$ for $\mathrm{Pa}^{+}$species. In the case of the $\mathrm{U}^{+}$and $\mathrm{Np}^{+}$ species the contribution of their $7 \mathrm{~s}$ orbitals to the SOMO is important. We note also a rather significant participation of the $\mathrm{CH}_{3} \mathrm{~F}$ group in the SOMO of the $\mathrm{Th}^{+}$species equal to $14.9 \%$. Thus, when $\mathrm{Ac}^{+}$and $\mathrm{Th}^{+}$react with $\mathrm{CH}_{3} \mathrm{~F}$ an electron is transferred from $6 \mathrm{~d}$ orbitals whereas 
when the other actinides react with $\mathrm{CH}_{3} \mathrm{~F}$ an electron is transferred mainly from the $5 \mathrm{f}$ but also from 7 s orbitals for $\mathrm{U}^{+}$and $\mathrm{Np}^{+}$.

Concerning the LUMO, we note also that the major contributions are metallic except for the triplet state $\mathrm{Ac}^{+} \mathrm{TS}$ structure for which $\mathrm{CH}_{3} \mathrm{~F}$ contributes to the FMO with an important weight of $53.2 \%$ (Fig. 6). It is noted that the $6 \mathrm{~d}$ orbitals weight remains low whereas the $5 \mathrm{f}$ weight in the other systems is important except the case of the $\mathrm{Am}^{+}$one, for which the weight of

$7 \mathrm{~s}$

is

dominating.

\section{Conclusion}

In the present work, the gas phase reactivity of a series of bare actinide monocations $\mathrm{An}^{+}$ towards fluoromethane $\mathrm{CH}_{3} \mathrm{~F}$, selected as a representative of systems exhibiting strong chemical bonds, was investigated using relativistic ZORA/DFT calculations. Intermediates and transition states structures have been characterized using LT and IRC calculations. The $\mathrm{C}-\mathrm{F}$ bond activation to form $\mathrm{AnF}^{+}$is the main reaction pathway; it proceeds by pure harpoon mechanism in $\mathrm{Pu}^{+}$and $\mathrm{Am}^{+}$systems, and by insertion-elimination mechanism in the $\mathrm{Th}^{+}, \mathrm{Pa}^{+}$, $\mathrm{U}^{+}$and $\mathrm{Np}^{+}$systems whatever their spin states. This study highlighted the atypical case of $\mathrm{Ac}^{+}$ for which the 'harpoon-like' mechanism occurs in its triplet state whereas the 'insertionelimination' is the suitable mechanism for its singlet state. The free energy diagrams show that the $\mathrm{An}^{+}+\mathrm{CH}_{3} \mathrm{~F}$ reactions $(\mathrm{An}=\mathrm{Ac}, \mathrm{Th}, \mathrm{Pa}, \mathrm{U}, \mathrm{Np}, \mathrm{Pu}, \mathrm{Am})$ are exergonic, and the calculated activation barriers are found generally low showing the ability of actinide cations especially the early actinide cations to activate the $\mathrm{C}-\mathrm{F}$ fluoromethane bond. Except for $\mathrm{Ac}^{+}$, the activation energy increases with the actinide atomic number. $\mathrm{The} \mathrm{Th}^{+}$reaction present the lower activation barrier, $0.9 \mathrm{kcal} / \mathrm{mol}$, and a considerable exergonic character with reaction energy of $-81.5 \mathrm{kcal} / \mathrm{mol}$ which makes this cation very efficient for this reaction. Based on these activation barriers results the following ordering of reactivity towards the $\mathrm{C}-\mathrm{F}$ activation can be presented: $\mathrm{Th}^{+} \geq \mathrm{U}^{+} \geq \mathrm{Pa}^{+} \geq \mathrm{Np}^{+}>\mathrm{Pu}^{+}>\mathrm{Am}^{+}$.

The Frontier Molecular Orbitals of transition structures (TS) for all actinide monocations exhibits an important metallic character, involving mainly the $6 \mathrm{~d}$ orbital for $\mathrm{Ac}^{+}$and $\mathrm{Th}^{+}$ systems and $5 \mathrm{f}$ for the other considered actinides, except the LUMO of $\mathrm{Ac}^{+}$species (triplet state) where fluoromethane contributes strongly. The electron transfer which occurs starting from the transition state from the actinide cation towards the $\mathrm{CH}_{3}-\mathrm{F}$ moiety, as indicated by MPA and Hirshfeld charges analyses, decreases with the actinide atomic number and 
proceeds from the $6 \mathrm{~d}$ metal orbitals for $\mathrm{Ac}^{+}$and $\mathrm{Th}^{+}$whereas it proceeds mainly from the $5 \mathrm{f}$ orbitals for the other systems but also from $7 \mathrm{~s}$ orbitals for $\mathrm{U}^{+}$and $\mathrm{Np}^{+}$.

\section{Supporting Information:}

SI.1: Total Bonding Energies of all reactions $\mathrm{An}^{+}+\mathrm{CH}_{3} \mathrm{~F}$

SI.2: Zero Point Vibration Energies (ZPVE)

SI.3: Vibration Frequencies $\left(\mathrm{cm}^{-1}\right)$

SI.4: Transition state frequency profiles

SI.5: Energy profiles

SI.6: Hirshfeld charge evolution during the reaction $\mathrm{An}^{+}+\mathrm{CH}_{3} \mathrm{~F}$

SI.7: Atomic coordinates of molecular structures for all the reactions $\mathrm{An}^{+}+\mathrm{CH}_{3} \mathrm{~F}$

SI.8: Mulliken Populations and Hirshfeld Charges Analyses

\section{Acknowledgements}

We thank the Algerian government for the research grant CNEPRU B00L02 UN 15012013 0025. Computing facilities were provided by ASELKAM of Mouloud Mammeri University of Tizi-Ouzou (Algeria) and IDRIS Computing Centre of CNRS (France).

\section{References}

[1] E. Di Santo, M.C. Michelini, N. Russo, Activation of ethane C-H and C $-\mathrm{C}$ bonds by gas phase $\mathrm{Th}^{+}$and $\mathrm{U}^{+}$: a theoretical study, J. Phys. Chem. A 113 (2009) 14699-14705.

[2] (a) L. Maron, L. Perrin, O. Eisenstein, A DFT study of $\mathrm{SiH}_{4}$ activation by $\mathrm{Cp}_{2} \mathrm{LnH}$, Dalton Trans. (2002) 534-539. (b) P.L. Arnold, M.W. Mc Mullon, J. Rieb, F.E. Kuhn, C-H bond activation by f-block complexes, Angew. Chem. Int. Ed. 54 (2015) 82-100.

[3] H.H. Cornehl, C. Heinemann, D. Schröder, H. Schwarz, Gas-phase reactivity of lanthanide cations with hydrocarbons, Organometallics 14 (1995) 992-999.

[4] K.J. de Almeida, H. A. Duarte, Dehydrogenation of methane by gas-phase $\mathrm{Th}, \mathrm{Th}^{+}$, and $\mathrm{Th}^{2+}$ : Theoretical insights into actinide chemistry, Organometallics 29 (2010) 3735-3745. 
[5] P.B. Armentrout, J.L. Beauchamp, Thermochemistry of uranium halide ions: reactions of uranium (+) with methyl fluoride, silicon tetrafluoride, methyl chloride and carbon tetrachloride, J. Phys. Chem. 85 (1981) 4103-4105.

[6] (a) P. Zhao, Y.C. Wang, Y. Sheng, Y.M. Jia, Theoretical study of $\mathrm{Ni}^{+}$assisted C-C and $\mathrm{C}-\mathrm{H}$ bond activations of propionaldehyde in the gas phase, Comp. Theor. Chem. 1114 (2017) 140-145. (b) C. Cheng, C.Y. Wang, P. Huai, Z.Y. Zhu, Structural and electronic properties of actinides fluorides: a density functional study, Procedia Chemistry 7 (2012) $460-465$.

[7] (a) P. Ma, Y.C. Wang, W.X. Wang, Z.P. Deng, G.P. Niu, X.L. Wang, Theoretical investigation on activation of $\mathrm{C}-\mathrm{H}$ and $\mathrm{C}-\mathrm{C}$ bonds, Comp. Theor. Chem.1085 (2016) 2330. (b) Y. Jin, Y. Wang, Z. Geng, H. Wang, Y. Gan, Competitive activation of C-H and C-F bonds in gas phase reaction of $\mathrm{Ir}^{+}$with $\mathrm{CH}_{3} \mathrm{~F}$ : A DFT study, J. Organometallic Chem. 717 (2012) 195-201.

[8] J. Harvey, D. Schrisder, W. Koch, D. Danovih, Electron-transfer reactivity in the activation of organic fluorides by bare metal monocations, Chem. Phys. Lett. 278 (1997) 391397.

[9] (a) J.K. Gibson, Gas-phase f-element organometallic chemistry: Reactions of cyclic hydrocarbons with $\mathrm{Th}^{+}, \mathrm{U}^{+}, \mathrm{ThO}^{+}, \mathrm{UO}^{+}$, and lanthanide ions, $\mathrm{Ln}^{+}$, Organometallics 16 (1997) 4214-4222. (b) J.K. Gibson, Gas-phase reactions of americium ion, $\mathrm{Am}^{+}$, with alkenes, Organometallics 17 (1998) 2583-2589. (c) J.K. Gibson, Gas-phase chemistry of actinide ions: probing the distinctive character of the $5 \mathrm{f}$ elements, Int. J. Mass. Spectrom. 214 (2002) 1-21. (d) J.K. Gibson, J. Marçalo, New developments in gas-phase actinide ionchemistry, Coord. Chem. Rev. 250 (2006) 776-783.

[10]E. van Lenthe, J.G. Snijders, E.J. Baerends, The zero-order regular approximation for relativistic effects: The effect of spin-orbit coupling in closed shell molecules, J. Chem. Phys. 105 (1996) 6505-6516.

[11] A. Elkechai, S. Meskaldji, A. Boucekkine, L. Belkhiri, D. Bouchet, M. Amarouche, C. Clappe, D. Hauchard, M. Ephritikhine, A relativistic DFT study of the electron affinity of thebiscyclopentadienyl uranium complexes $\mathrm{Cp} *_{2} \mathrm{UX}_{2}$, J. Mol. Struct. (theochem) 954 (2010) 115-123.

[12]K.J. de Almeida, A. Cesar, Methane C-H Bond Activation by Neutral Lanthanide and Thorium Atoms in the Gas Phase: A Theoretical Prediction, Organometallics 25 (2006) 3407-3416. 
[13] A. Matsuda, H. Mori, Theoretical study of lanthanide mono cation-mediated C-F bond activation, Chem. Phys. 380 (2011) 48-53.

[14] K.J. de Almeida, H.A. Duarte, Gas-phase methane activation by the $\mathrm{Ac}^{+}-\mathrm{Pu}^{+}$ions : Theoretical insights into the role of $5 \mathrm{f}$ electrons/orbitals in early actinide chemistry, Organometallics 28 (2009) 3203-3211.

[15] H.H. Cornehl, G. Hornung, H. Schwarz, Gas-phase reactivity of lanthanide cations with fluorocarbons: $\mathrm{C}-\mathrm{F}$ versus $\mathrm{C}-\mathrm{H}$ and $\mathrm{C}-\mathrm{C}$ bond activation, J. Am. Chem. Soc. 118 (1996) 9960-9965.

[16] G.K. Koyanagi, X. Zhao, V. Blagojevic, M.J.Y. Jarvis, D.K. Bohme, Gas-phase reactions of atomic lanthanide cations with methyl fluoride: periodicities reactivity, Int. J. Mass. Spectrom. 241 (2005) 189-196.

[17]D. Zhang, C. Zhang, C. Liu, Density functional studies of the reactivity in the C-F bond activation of fluoromethane by bare lanthanum monocation, ,J. Organomet. Chem. 640 (2001) 121-126.

[18]D. Zhang, C. Liu, S. Bi, Density functional studies of the reactions of lanthanide monocations with fluoromethane: $\mathrm{C}-\mathrm{F}$ bond activation and electron-transfer reactivity, $\mathrm{J}$. Phys. Chem. A, 106 (2002) 4153-4157.

[19] Y.C. Wang, Z.Y. Liu, Z. Geng, X.Y. Yang, Theoretical investigation of the reactivity in the $\mathrm{C}-\mathrm{F}$ bond activation of $\mathrm{CH}_{3} \mathrm{~F}$ by $\mathrm{La}^{+}$in the gas phase, J. Mol. Struct. (Theochem) 765 (2006) 27-34.

[20]Z.Y. Liu, Y.C. Wang, Z.Y. Geng, X.Y. Yang, H.Q. Wang, Theoretical investigation of the reactivity in the $\mathrm{C}-\mathrm{F}$ bond activation of $\mathrm{CH}_{3} \mathrm{~F}$ by $\mathrm{Lu}^{+}$in the gas phase, Chem. Phys. Lett. 431 (2006) 223-226.

[21] K.J. de Almeida, Methane dehydrogenation by niobium ions: a first-principles study of the gas-phase catalytic reactions, Organometallics 32 (2013) 989-999.

[22]P. Hohenberg, W. Kohn, Inhomogeneous electron gas, Phys. Rev. 136 (1964) B864B871.

[23]W. Kohn, L.J. Sham, Self-consistent equations including exchange and correlation effects, Phys. Rev. 140 (1965) A1133-A1138.

[24] R.G. Parr, W. Yang, Density-Functional Theory of Atoms and Molecules, Oxford University Press, UK (1989).

[25]E. Van Lenthe, E.J. Baerends, J.G. Snijders, Relativistic regular two-component Hamiltonians, J. Chem. Phys. 99 (1993) 4597-4610. 
[26]E. Van Lenthe, E.J. Baerends, J.G. Snijders, Relativistic total energy using regular approximations, J. Chem. Phys. 101 (1994) 9783-9792.

[27]E. Van Lenthe, A. Ehlers, E.J. Baerends, Geometry optimizations in the zero order regular approximation for relativistic effects, J. Chem. Phys. 110 (1999) 8943-8953.

[28] G.C. Fonseca, J.G. Snijders, G. te Velde, E.J. Baerends, Towards an order-N DFT method, Theor. Chem. Acc. 99 (1998) 391-403.

[29] G. te Velde, F.M. Bickelhaupt, S.A.J. van Gisbergen, G.C. Fonseca, E.J. Baerends, J.G. Snijders, T. Ziegler, Chemistry with ADF, J. Comput. Chem. 22 (2001) 931-967.

[30]ADF2014.01, SCM, Theoretical Chemistry. Vrije University, Amsterdam, the Netherlands, http://www.scm.com.

[31] S.D. Vosko, L. Wilk, M. Nusair, Accurate spin-dependent electron liquid correlation energies for local spin density calculations: a critical analysis, Can. J. Chem. 58 (1990) $1200-1211$.

[32](a) A.D. Becke, Density functional calculations of molecular bond energies, J. Chem. Phys. 84 (1986) 4524-4529. (b) A.D. Becke, Density-functional exchange-energy approximation with correct asymptotic behavior, Phys. Rev. A 38 (1988) 3098-3100. (c) J.P. Perdew, Density-functional approximation for the correlation energy of the inhomogeneous electron gas, Phys. Rev. B 33 (1986) 8822-8824. (d) J.P. Perdew, Erratum for ref 32c, Phys. Rev. B, 34 (1986) 7406. (e) J.P. Perdew, Y. Wang, Accurate and simple analytic representation of the electron-gas correlation energy, Phys. Rev. B 45 (1992) 13244-13249.

[33] G. Ricciardi, A. Rosa, E. J. Baerends, S. A. J van Gisbergen, Electronic structure, chemical bond, and optical spectra of metal bis (porphyrin) complexes: a DFT/TDDFT study of the bis (porphyrin) M (IV) (M= Zr, Ce, Th) series, J. Am. Chem. Soc. 124 (2002) 12319-12334.

[34]N. Kaltsoyannis, Recent developments in computational actinide chemistry, Chem. Soc. Rev. 32 (2003) 9-16.

[35] A. Elkechai, A. Boucekkine, L. Belkhiri, M. Amarouche, C. Clappe, D. Hauchard, M.

Ephritikhine, A DFT and experimental investigation of the electron affinity of the triscyclopentadienyl uranium complexes $\mathrm{Cp}_{3} \mathrm{UX}$, Dalton Trans. (2009) 2843-2849.

[36] (a) A. Elkechai, Y. Mani, A. Boucekkine, M. Ephritikhine, Density functional theory investigation of the redox properties of tricyclopentadienyl-and phospholyluranium (IV) chloride complexes, Inorg. Chem. 51 (2012) 6943-6952. (b) A. Elkechai, F. Kias. F. 
Talbi, A. Boucekkine, Redox properties of biscyclopentadienyl uranium(V) imido-halide complexes: a relativistic DFT study, J. Mol. Model. 20 (2014) 2294-2304.

[37] MOLEKEL4.3, P. Flükiger, H.P. Lüthi, S. Portmann, J. Weber, Swiss Center for Scientific Computing, Manno, Switzerland, 2000, http://www.cscs.ch.

[38]E. Van Lenthe, J.G. Snijders, E.J. Baerends, The zero-order regular approximation for relativistic effects: the effect of spin-orbit coupling in closed shell molecules, J. Chem. Phys. 105 (1996) 6505-6516.

[39] (a) M.C. Michelini, N. Russo, E. Sicilia, How can uranium ions $\left(\mathrm{U}^{+}, \mathrm{U}^{2+}\right)$ activate $\mathrm{O}-\mathrm{H}$ bond of water in the gas-phase?, Angew. Chem. Int. Ed. 45 (2006) 1095-1099. (b) M.C. Michelini, N. Russo, E. Sicilia, Gas-phase chemistry of actinide ions : New insights into the reaction of $\mathrm{UO}^{+}$and $\mathrm{UO}^{2+}$ with water, J. Am. Chem. Soc., 129 (2007) 4229-4239. (c) G. Mazzone, M.C. Michelini, N. Russo, E. Sicilia, Mechanistic aspects of the reaction of $\mathrm{Th}^{+}$and $\mathrm{Th}^{2+}$ with water in the gas phase, Inorg. Chem. 47 (2008) 2083-2088.

[40] (a) J.T. Lyon, L. Andrews, P. Malmqvist, B.O. Roos, T. Yang, B.E. Bursten, Infrared spectrum and bonding in uranium methylidene dihydride, $\mathrm{CH}_{2}-\mathrm{UH}_{2}$, Inorg. Chem. 46 (2007) 4917-4925. (b) L. Gagliardi, B.O. Roos, P. Malmqvist, J.M. Dyke, On the Electronic Structure of the $\mathrm{UO}_{2}$ Molecule, J. Phys. Chem. A 105 (2001) 10602-10606. (c) A. Montoya, T.N. Truong, A.F. Sarofim, Spin Contamination in Hartree-Fock and Density Functional Theory Wavefunctions in Modeling of Adsorption on Graphite, J. Phys. Chem. A 104 (2000) 6108-6110.

[41] C. Gonzalez, H.B. Schlegel, An improved algorithm for reaction path following, J. Chem. Phys. 90 (1989) 2154-2161.

[42]F.L. Hirshfeld, Bonded-atom fragments for describing molecular charge densities, Theor. Chim. Acta 44 (1977) 129-138.

[43] (a) H.H. Cornehl, C. Heinemann, D. Schröder, H. Schwarz, Gas-phase reactivity of lanthanide cations with hydrocarbons, Organometallics 14 (1995) 992-999. (b) H.H. Cornehl, G. Hornung, H. Schwarz, Gas-Phase Reactivity of Lanthanide Cations with Fluorocarbons: $\mathrm{C}-\mathrm{F}$ versus $\mathrm{C}-\mathrm{H}$ and $\mathrm{C}-\mathrm{C}$ Bond Activation, J. Am. Chem. Soc. 118 (1996) 9960-9965.

[44] R.D. Shannon, Revised effective ionic radii and systematic studies of interatomic distances in halides and chalcogenides, Acta Crystallogr. Sect. A 32 (1976) 751-767. 